\title{
The Role of Myeloid-Derived Suppressor Cells in Viral Infection
}

\author{
Megan A. O'Connor,, ${ }^{1, * *}$ Jessica L. Rastad, ${ }^{1, *}$ and William R. Green ${ }^{1,2}$
}

\begin{abstract}
Myeloid-derived suppressor cells (MDSCs) are heterogeneous immature myeloid cells that are well described as potent immune regulatory cells during human cancer and murine tumor models. Reports of MDSCs during viral infections remain limited, and their association with immunomodulation of viral diseases is still being defined. Here, we provide an overview of MDSCs or MDSC-like cells identified during viral infections, including murine viral models and human viral diseases. Understanding the similarities and/or differences of virally induced versus tumor-derived MDSCs will be important for designing future immunotherapeutic approaches.
\end{abstract}

Keywords: MDSCs, viral infections, immunotherapeutic approaches

\section{Introduction}

\section{Myeloid-derived suppressor cell phenotype}

$\mathbf{T}$ HE ROLE OF MYELOID-DERIVED SUPPRESSOR CELLS (MDSCs) during viral infection is not well defined; however, MDSCs have been heavily studied in the context of human cancer and murine tumor models and have been revealed to contribute to the immunosuppressive tumor microenvironment [reviewed in Refs. (10,101,150)]. MDSCs dampen T cellmediated immune responses against several types of cancer, including melanoma, and lung, mammary, and colon carcinomas $(94,140,143)$. These myeloid cells, or a subset, may have been initially included in studies that identified natural suppressor (NS) cells capable of inhibiting cytotoxic T lymphocyte (CTL) activity. MDSCs are currently well characterized as primary cellular immune modulators of the tumor microenvironment, along with $\mathrm{CD}^{+}$regulatory T cells (Tregs) $(4,101,150$, , .

The nomenclature used to categorize these heterogeneous cell populations has been diverse, including NS cells, immature myeloid cells (IMCs), and myeloid suppressor cells, until reaching a consensus of "myeloid-derived suppressor cells" (46,150). Murine MDSCs are phenotypically defined as $\mathrm{CD}_{1} 1 \mathrm{~b}^{+} \mathrm{GR} 1^{+}$. Because the anti-GR1 mAb binds both Ly6C and Ly6G, MDSCs are further subdivided into Ly6G ${ }^{-\prime}$ ${ }^{\text {low Ly6C }}{ }^{+/ \text {high }}$ monocytic (M-MDSCs), which appear similar to monocytes with a large, round nucleus, and $\mathrm{Ly} 6 \mathrm{G}^{+/ \text {high- }}$ Ly6C $^{- \text {llow }}$ granulocytic (G-MDSCs or PMN-MDSCs), which have been described as having a multilobed nuclei somewhat similar to those seen in polymorphonuclear cells $(26,47,115,150)$.

A recent review, primarily focused on MDSCs in tumor systems, has advocated the use of the term PMN-MDSC over G-MDSC (10). However, most current publications refer to these cells as G-MDSCs. A third subset, termed immature or early-stage MDSCs, has been observed by several groups in human cancers, but a murine equivalent has not yet been identified, and there are few if any reports of this subset in viral infections (10,93). Murine MDSCs display varying coexpression of other surface markers, including but not limited to, TLR4, F4/80, Fc $\gamma$ RIII/II (CD16/ 32), IL-4R $\alpha$ (CD124), and/or CD115 (47,94,140).

Phenotypic identification and classification of human MDSCs are more difficult, but the general consensus definition is $\mathrm{CD}_{3} 3^{+} \mathrm{CD} 11 \mathrm{~b}^{+} \mathrm{LIN}^{-} \mathrm{HLA}-\mathrm{DR}^{-}$cells. Human MDSCs can be further subdivided into CD14 ${ }^{+/ \text {dull }}$ M-MDSCs and $\mathrm{CD} 14^{-} \mathrm{CD} 15^{+}$G-MDSCs (150), although variations in these definitions remain. Additional information about the different phenotypes attributed to human MDSCs can be found in the 2012 review by Poschke and Keissling (121). Murine and human MDSCs may also express different combinations of chemokine receptors needed for egress of MDSCs out of the bone marrow and/or migration to tumor sites or sites of infection, such as CCR2, CXCR4, CXCR2, and/or $\mathrm{CX}_{3} \mathrm{CR} 1(9,58,62,68,86,111,112,133,138,173,176)$.

\footnotetext{
${ }^{1}$ Department of Microbiology and Immunology, Geisel School of Medicine at Dartmouth, Lebanon, New Hampshire.

${ }^{2}$ Norris Cotton Cancer Center, Geisel School of Medicine at Dartmouth, Lebanon, New Hampshire.

*These authors contributed equally to this work and Washington National Primate Research Center (WaNPC).

**Present address: Department of Microbiology, University of Washington, Seattle, Washington.
} 
As IMCs, MDSCs share phenotypic characteristics with other innate immune cells, including neutrophils, dendritic cells, macrophages, or monocytes, leading to variations in MDSC nomenclature. Although there may well be some plasticity associated with a continuum of many of these cells, murine MDSCs have increased surface expression of GR1 and are functionally immature compared to tumor-associated macrophages (TAMs) $(123,150)$.

As the cell surface phenotype of MDSCs is similar to that of other cells (i.e., monocytes and neutrophils), it is critical to show suppressive function to properly identify MDSCs, at least until unequivocal MDSC markers are identified (10). Because quantifying in situ/in vivo suppressive function is generally challenging, MDSCs are typically isolated ex vivo from virus-infected hosts or derived in vitro from precursor cells, and suppression is measured by their inhibition of cytokine production and/or proliferation of responder $\mathrm{T}$ cells (10). Cells that meet the phenotypic criteria and are suppressive of (at least) $\mathrm{T}$ cell functions can be documented as MDSCs (10).

Alternatively, if suppressive activity is not determined, but biochemical characteristics indicate the cells may be MDSCs (including transcription factor and regulator expression (e.g., IRF8, phospho-STAT3, c/EBP $\beta$, S100A8/A9, or Rb1), upregulation of cytokines and their receptors, and/or presence/production of immune-regulatory molecules), cells should be recognized as MDSC-like cells (MDSC-LCs) (10). A detailed description of the criteria for identifying MDSCs can be found in the referenced review (10). In this context, MDSCs during viral infection may be substantially underreported and/or identified as other myeloid cell types. Furthermore, MDSC-LCs have been phenotypically identified in several viral systems, but often were not tested for suppressive activity. The following discussion identifies studies that demonstrate or support a role of MDSCs or MDSC-LCs (as defined by phenotype and/or function) during viral infection.

\section{Immune Target Cell Specificity of MDSCs}

MDSCs or MDSC-LCs isolated from virus-infected patients and/or from animal viral models suppress several immune cell targets and use a variety of immunosuppressive mechanism(s) to modulate immune responses (Table 1).

\section{T cells}

MDSCs from a variety of viral infections, including but not limited to nonretroviral RNA viruses as featured below, are able to suppress T cell responses. MDSCs isolated from hepatitis $\mathrm{C}$ virus (HCV)-infected patient peripheral blood mononuclear cells (PBMCs) or derived in vitro, by coculturing $\mathrm{CD}_{3}{ }^{+}$mononuclear cells with hepatocytes infected with $\mathrm{HCV}$ or treated with $\mathrm{HCV}$ core protein, inhibited polyclonal $\mathrm{CD} 4^{+}$ and $\mathrm{CD}^{+} \mathrm{T}$ cell proliferation and production of interferon (IFN)- $\gamma$ and IL-2 (14,148). Lung MDSCs from influenza A virus (IAV)-infected mice and $\mathrm{CD} 11 \mathrm{~b}^{+}$cells isolated from the PBMCs of patients with a recent IAV infection inhibited Agspecific proliferation of T cells (31).

Interestingly, splenic M-MDSCs from mice infected with the C13 chronic lymphocytic choriomeningitis virus (LCMV) strain, but not the Armstrong acute LCMV strain, suppressed Ag-specific $\mathrm{CD}^{+} \mathrm{T}$ cell proliferation (109). These data may indicate that chronic inflammation is a driver for MDSC development. Alternatively, expansion of MDSCs driven by immune responses to some, but not all, acute infections may contribute to the development of chronic inflammation.

Retroviral infection also induces MDSCs. In vitro derived MDSCs, via stimulation of PBMCs with the HIV glycoprotein 120 (gp120), or ex vivo MDSCs derived from HIVinfected patient blood inhibited polyclonal and Ag-specific $\mathrm{CD}^{+}$and $\mathrm{CD}^{+} \mathrm{T}$ cell proliferation and IFN- $\gamma$ production $(8,50,122,155)$ and increased FoxP3 ${ }^{+} \mathrm{CD}^{+}$Treg differentiation (159). In these studies, inhibitory activity was independent of the phenotype of the MDSCs, which were either monocytic like $(8,50,122)$ or granulocytic like $(155)$.

Similarly, M-MDSCs isolated from circulation in simian immunodeficiency virus (SIV)-infected macaques inhibited polyclonal and $\mathrm{Ag}$-specific $\mathrm{CD} 8^{+} \mathrm{T}$ cell proliferation (146). During infection with LP-BM5, a murine retrovirus, which causes profound immunodeficiency similar to HIV/AIDS (termed MAIDS) $(2,15,153)$, and splenic M-MDSCs inhibited polyclonal $\mathrm{CD}^{+}$and $\mathrm{CD}^{+} \mathrm{T}$ cell proliferation and IFN- $\gamma$ production (53).

MDSCs have also been indentified during DNA virus infection. MDSCs accumulated in hepatitis B virus (HBV)infected patients, with preferential expansion of G-MDSCs, rather than M-MDSCs, both in circulation and in the liver (92,116). Ex vivo G-MDSCs from $\mathrm{HBV}$-infected patients or derived from a murine model of HBV infection, inhibited Agspecific and polyclonal $\mathrm{CD} 4^{+}$and $\mathrm{CD}^{+} \mathrm{T}$ cell proliferation and IFN- $\gamma$ production $(20,116)$.

Inflammatory monocytes, with an M-MDSC phenotype, derived from murine cytomegalovirus (MCMV)-infected mice also suppressed ex vivo MCMV-specific CTL responses and cytokine polyfunctionality (30). MDSCs or MDSC-LCs accumulated in HSV-1-infected corneas $(34,130,154)$, but it remains unclear whether these cells demonstrated inhibitory activity. In one study, $\mathrm{F} 4 / 80^{-} \mathrm{GR} 1^{+}$cells accrued in the corneas of HSV-1-infected mice and the authors concluded, based on nuclear morphology, that these infiltrating cells were not MDSCs, however, functional studies were not provided (130).

\section{$C D 4^{+} T$ cell functional and phenotypic subsets}

In addition to suppressing $\mathrm{CD}^{+}$and $\mathrm{CD}^{+} \mathrm{T}$ cell proliferation and IFN- $\gamma$ production, MDSCs can also modulate $\mathrm{CD}^{+}{ }^{+} \mathrm{T}$ helper (Th) cell polarization. IL-10 and TNF- $\alpha$ produced by MDSCs isolated from IAV-infected mice mediated skewing to $\mathrm{CD}^{+}{ }^{+} \mathrm{Th} 2$ cells (72).

Alternatively, incubation of PBMCs with MDSCs derived from $\mathrm{HCV}$-infected patients resulted in increased numbers of Tregs (128). Increased Treg frequencies have been observed in HIV-infected patients and were correlated with increased MDSC frequency (155). Furthermore, M-MDSCs derived in vitro or isolated from HIV-infected patients induced $\mathrm{CD}^{+}{ }^{+} \mathrm{FoxP}^{+}$Treg expansion and production of IL10 by $\mathrm{CD}^{+} \mathrm{T}$ cells (presumably by these Tregs) in vitro $(50,155)$. In the mouse retrovirus immunodeficiency system, ex vivo derived M-MDSCs from LP-BM5-infected mice also induced a moderate expansion of Tregs in vitro, but concurrently suppressed their IL-10 production (114). Together, these studies support a relationship between $\mathrm{CD}^{+}{ }^{+}$FoxP3 $^{+}$ Tregs and MDSCs in viral systems. 


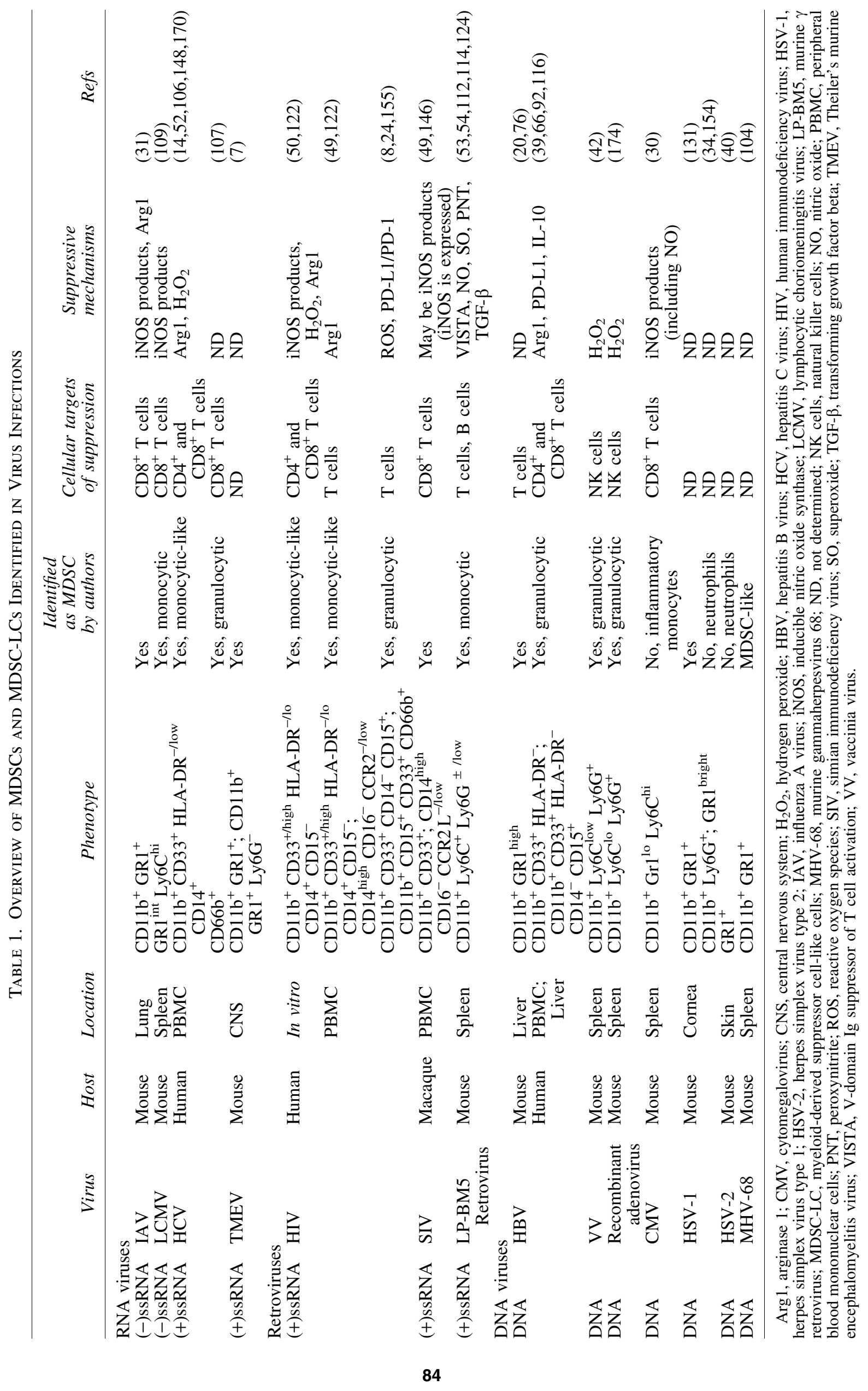




\section{B cells}

Despite the large number of studies in tumor systems that demonstrate MDSC-mediated suppression of $\mathrm{T}$ cell responses, only a few reports have discussed the ability of myeloid-lineage cells to suppress B cell responses: for example, in two early studies by Mac- $1^{+} 2^{+}$MDSC-LCs $(44,162)$. More recent study showed that MDSCs in the bone marrow of aged mice suppressed B cell lymphopoiesis in an IL-1-dependent manner (74,75). B cells play crucial roles in cancer as sources of malignant cells in several lymphomas (136) and as sources of tumor-specific antibodies (144). In autoimmunity, B cell self-tolerance is frequently defective, causing production of pathogenic, autoreactive antibodies and increases in the size of the memory B cell pool (35). M-MDSCs in a collagen-induced arthritis model were shown to suppress both $\mathrm{T}$ and B cells (29).

More relevant to this review, in viral disease, B-lineage cells play a variety of crucial roles: plasma cells produce antibodies to prevent or contain viral infection, and memory B cells allow for fast, more adaptive antibody production following rechallenge (36). In the mouse retrovirus immunodeficiency system, MAIDS, M-MDSCs derived from LPBM5 retrovirus-infected mice suppressed polyclonal B cell proliferative and IL-10 producing B-regulatory (Breg) responses $(53,124)$. Of note, no suppression of B (or T) cell responses was observed by Ly6G-enriched splenocytes (which contain G-MDSCs) in this system (53). To our knowledge, suppression of the B cell compartment has only been observed by M-MDSCs, and studies have not yet identified G-MDSC suppression of B cells.

\section{Other cellular targets}

G-MDSCs from vaccinia (42) and adenoviral vector (174)infected mice inhibited natural killer (NK) cell responses. Whether MDSCs from these two models also suppress T or B cell responses remains to be determined. In a mouse mammary tumor model, MDSCs impaired antitumor T cell responses by direct suppression of $\mathrm{T}$ cells and also by indirect modulation of macrophages that skewed the T cell milieu (141). However, to our knowledge, a similar interaction between MDSCs and macrophages has not been described during viral infections.

\section{Early Studies of Molecular Mechanisms of MDSC Suppression: T Cell Targets}

The major mechanisms of suppression by MDSCs, primarily discovered in tumor systems, include catabolism of L-arginine (L-Arg) by arginase 1 (Arg1) and/or inducible nitric oxide synthase (iNOS); production of reactive oxygen species (ROS); production of immunosuppressive cytokines; or negative checkpoint regulators (i.e., V-domain Ig suppressor of $\mathrm{T}$ cell activation [VISTA], also known as PD-1H) $(41,54,158)$.

Broadly, G-MDSCs and M-MDSCs preferentially express Arg1 or iNOS, respectively, but both enzymes can be coexpressed within the same cell (26). Several cross-inhibitory interactions have been reported between the Arg1 and iNOS pathways $(12,13,125)$. Arg1 has a lower affinity for L-Arg, but catalyzes the reaction faster than iNOS, and thus, their overall rates of conversion of L-Arg are relatively similar (12). Understanding the requirements of expression of Arg1 and/or iNOS, including gene expression, cytokine inducibility, and/or meta- bolic programming, is needed to determine the fine regulation of these two suppressive mechanisms utilized by MDSCs.

\section{Inducible nitric oxide synthase}

There are three isoforms of NOS: NOS1 or neuronal NOS (nNOS), NOS2 or iNOS found in myeloid cells, and NOS3 (eNOS) found in endothelial cells $(12,163)$. iNOS expression in myeloid cells is driven by Th1 cytokines, including IFN- $\gamma$, as well as by IL- 1 , TNF- $\alpha$, IFN- $\alpha$, and IFN- $\beta$ (12). Metabolism of L-Arg by iNOS produces NO and citrulline $(125,129)$. NO-mediated suppression may be caused by direct S-nitrosylation of cysteine residues and/or indirect activation of soluble guanylate cyclase and cyclic-GMP-dependent protein kinases, which alter IL-2 signaling in T cells (12).

\section{$\operatorname{Arg} 1$}

Of two isoforms, $\operatorname{Arg} 2$ is constitutively expressed in mitochondria of a variety of nonhepatic cells, including renal cells, neurons, macrophages, and enterocytes, with limited expression in the liver $(12,163)$. In contrast, Arg1, located in the cytoplasm of hepatocytes and myeloid cells, including MDSCs $(12,163)$, is cytokine inducible (by Th2 cytokines, including IL-4, IL-13, and IL-10) in mouse myeloid cells, but is constitutively expressed in human myeloid cells $(12,163)$. It is tempting to speculate that the constitutive expression of Arg1 in human MDSCs may predispose them to favor suppression by Arg1, as opposed to iNOS, however, this has not been definitively shown. The main mechanism by which arginine catabolism inhibits $T$ cell function may be by depletion of extracellular L-Arg and urea production, resulting in loss of $\mathrm{CD} 3 \zeta$ expression, but other mechanisms, such as decreased mRNA translation, have been considered (12).

\section{Reactive nitrogen and oxygen species}

Low L-Arg concentrations can also promote production of superoxide anion $\left(\mathrm{O}_{2}^{-}\right)$, which may act on its own but can further participate in the formation of reactive nitrogen species (RNS) and other ROS (12). Cytokines such as transforming growth factor beta (TGF- $\beta$ ), IL-3, IL-6, and IL-10 induce ROS production by MDSCs (132). $\mathrm{O}_{2}^{-}$can interact with $\mathrm{NO}$ to form peroxynitrites $\left(\mathrm{ONOO}^{-}\right)$or with protons to form hydrogen peroxide $\left(\mathrm{H}_{2} \mathrm{O}_{2}\right)$ (12). RNS and ROS promote apoptosis of target cells by inducing post-translational protein modifications, including nitrating tyrosine residues, or increasing CD95 and downregulating BCL-2 in activated cells $(12,163)$. High ROS production may prevent differentiation of IMCs, leading to increased MDSC numbers as a positive feedback loop (79).

\section{Other mechanisms}

Other mechanisms of suppression associated with MDSCs in tumor or other nonviral systems include upregulation of negative checkpoint regulators, such as PD-1/PD-L1, on MDSCs from cancer patients $(3,171)$. MDSC-mediated suppression was shown to be PD-L1 dependent in a study of immunotherapy for human colorectal cancer liver metastasis (152) as well as in a study of pneumocystis pneumonia (85).

MDSCs can also suppress cells by the production of immunosuppressive cytokines: for example, MDSC-derived IL-10 was shown to suppress T cell and macrophage effector 
function in murine models of ovarian cancer, mammary carcinoma, and colorectal carcinoma $(5,57)$. Furthermore, in the ovarian cancer model, IL-10 signaling to MDSCs through IL-10R was required for the suppressive phenotype of the MDSCs (57). MDSC IL-10 production was also implicated in the resolution of inflammation in bacterial pneumonia (120). Another immunosuppressive cytokine, TGF- $\beta$, was produced by MDSCs in several murine tumor models $(23,87,88,168)$.

\section{MDSC Suppression in Viral Infections: Target Cells and Mechanisms}

\section{Nonretroviral RNA viruses}

The mechanisms mentioned above are used either individually or in combination by MDSCs during infection with viruses, including nonretroviral RNA viruses discussed below (Table 1). In HCV, MDSC frequencies from chronically infected patients directly correlated with liver Arg1 levels (170). MDSCs from $\mathrm{HCV}$-infected patients inhibited ex vivo $\mathrm{CD}^{+}{ }^{+}$and $\mathrm{CD}^{+} \mathrm{T}$ cell responses via Arg1 (14). In another study, MDSCs, induced by exposing PBMCs to HCV, suppressed NK cells, also via Arg1 (52). Decreased TCR $\zeta$ expression was observed on liver $\mathrm{CD}^{+} \mathrm{T}$ cells from chronically infected HCV patients, whereas expression increased in infected patients receiving pegylated-IFN- $\alpha /$ ribavirin antiviral therapy (170). TCR $\zeta$ expression was restored in ex vivo $\mathrm{T}$ cell cultures from $\mathrm{HCV}$-infected patients when supplemented with L-Arg (170).

Another group observed increased ROS production by cells with an M-MDSC-like phenotype in the peripheral blood of chronically infected $\mathrm{HCV}$ patients, but did not confirm their ex vivo suppressive capability (148). In the same study, M-MDSCs derived in vitro, by coculturing $\mathrm{CD}_{3} 3^{+}$ mononuclear cells with $\mathrm{HCV}$ core protein or hepatocytes infected with HCV, utilized ROS to suppress T cells (148).

$\mathrm{CD} 1 \mathrm{~b}^{+}$cells isolated from the peripheral blood of patients with a recent IAV infection suppressed $\mathrm{T}$ cells in an iNOS- and Arg1-dependent manner, which was also observed for MDSCs from IAV-infected mice (31). Inhibition of immune responses by M-MDSCs from LCMV C13 chronically infected mice was dependent on iNOS (109).

\section{Retroviruses}

In the handful of recent studies of MDSCs derived ex vivo from HIV-infected patients $(8,122,155)$ or induced in vitro by stimulation of PBMCs with HIV gp120 (50), the mechanisms of immune suppression appear to be diverse, including iNOS (50), ROS (50), Arg1 (122), and the PD-L1/ PD-1 pathway (8), while in some cases the mechanism(s) involved were not examined (155). In most cases, these cells displayed a monocytic-like phenotype $(8,50,122)$, however, a granulocytic-like phenotype was observed in one study (155). The mechanism of suppression of $\mathrm{T}$ cell responses by M-MDSCs from SIV-infected macaques has not been definitively determined, but may be linked to high iNOS expression by the MDSCs $(49,146)$.

M-MDSCs derived from mice infected with LP-BM5 retrovirus suppressed $\mathrm{T}$ cell responses in a predominantly iNOS/NO-mediated manner (53). Genetic ablation of indoleamine 2,3-deoxygenase (IDO) did not affect MDSCmediated suppression; however, IDO may function in wild- type MDSCs from LP-BM5-infected mice and be compensated for by other mechanisms in the $I D O$-knockout MDSCs (113). Supporting a potential role for IDO in LP-BM5, overall $I D O$ is increased during MAIDS and may play a role in the associated pain hypersensitivity $(65,69,113)$. Current data are conflicting as to whether increased $I D O$ plays a role in LP-BM5 retrovirus replication and immunodeficiency $(65,113)$.

Suppression of B cell responses by these same M-MDSCs from LP-BM5-infected mice was mediated not only, in part, by iNOS/NO (53) but also substantially by the negative checkpoint regulator VISTA $(41,54,158)$, and by ROS, RNS, and TGF- $\beta$ (Fig. 1a) (124). Further division of MMDSCs from LP-BM5-infected mice into subpopulations revealed differential dependence on iNOS-mediated suppression (112) and highlighted the phenotypic and functional heterogeneity of these cells (Fig. 1b).

A pie chart showing the different mechanisms used by MMDSCs from LP-BM5 infected mice and their relative contributions to suppression of B cells can be seen in Figure 2. The studies of M-MDSCs in the LP-BM5 system highlight several more general characteristics of MDSCs, including having multiple cellular targets, contact-dependent and soluble suppressive mechanisms, and heterogeneity of phenotype and mechanism among subsets.

\section{DNA viruses}

MDSCs from patients and mice infected by DNA viruses have also been shown to be capable of expressing Arg1 and iNOS, and to produce ROS. In HBV-infected patients, GMDSC frequency correlated positively with increased Arg1 concentrations and inversely with $\mathrm{CD} 3 \zeta$ expression on T cells (116). Consistent with this observation, ex vivo G-MDSCs from HBV-infected patients in the same study suppressed in vitro $\mathrm{T}$ cell responses in an Arg1-dependent manner (116). Another study, however, found that MDSCs from chronically $\mathrm{HBV}$-infected patients suppressed $\mathrm{CD}^{+}$ $\mathrm{T}$ cell proliferation, IFN- $\gamma$ production, production of granzyme B and perforin, and degranulation in a manner dependent on PD-1-induced IL-10 production (66). In the HBV transgenic murine model of persistent HBV infection without significant pathology, in which the complete HBV genome is injected into fertilized eggs, ex vivo Arg1- and iNOS-dependent suppression of $\mathrm{T}$ cells by MDSCs was observed $(20,76)$.

G-MDSCs from vaccinia- or adenovirus-infected mice used ROS to suppress NK cells $(42,174)$, but it remains to be determined whether ROS production by these cells also modulated other immune cell responses.

Despite early identification of cells with an MDSC-like surface phenotype in murine corneal HSV-1 infection, suppressive activity of these cells, to our knowledge, was not reported (131). In another study, total corneal iNOS and Arg1 mRNA levels increased during murine HSV-1 infection (98). Increased $\mathrm{NO}$ and $\mathrm{H}_{2} \mathrm{O}_{2}$ production by human PMNs (with MDSC-like properties) was observed when incubated with the supernatants of corneal cells treated with HSV components (60). Collectively, these data suggest that MDSC-LCs derived during HSV infection may be able to utilize several mechanisms to suppress inflammation. 


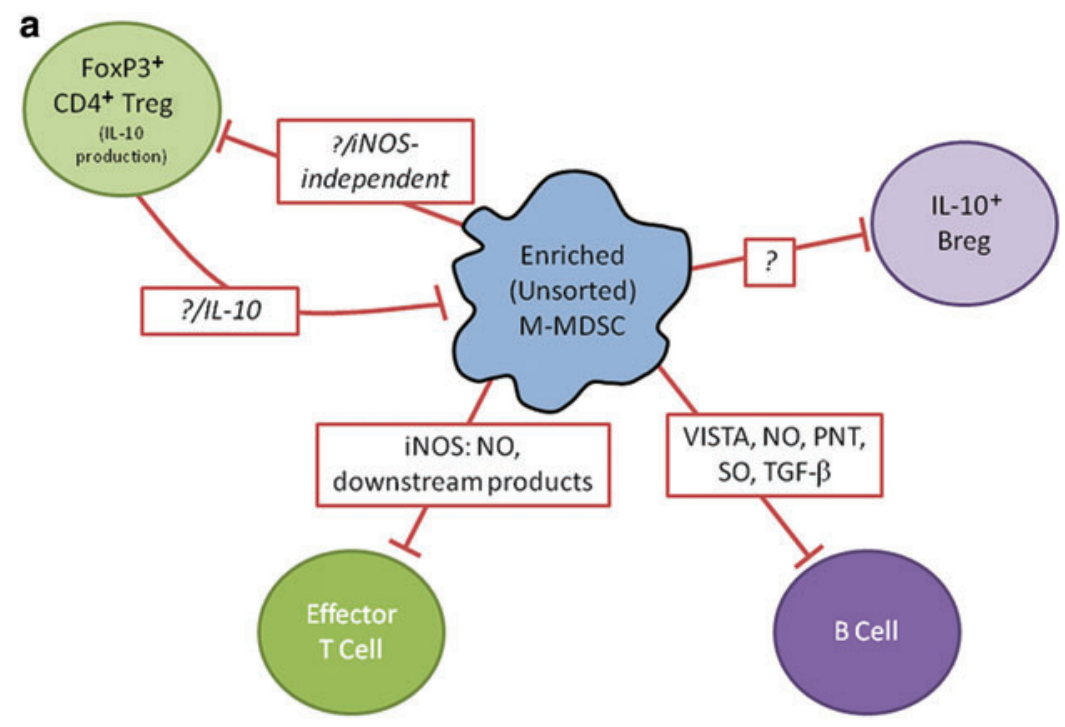

b

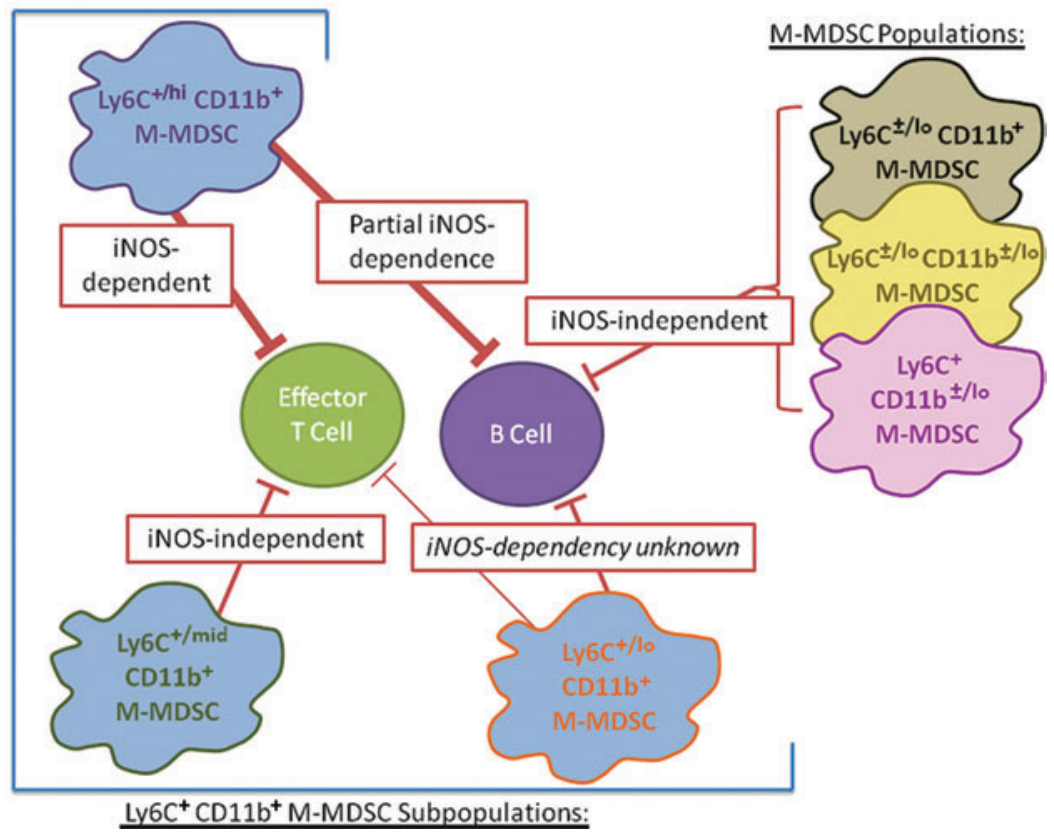

FIG. 1. Overview of interactions between M-MDSCs, Tregs, and immune cell targets during LP-BM5 infection. (a) Lines indicate suppressive relationships based on in vitro (M-MDSC-mediated suppression) and in vivo (CD4 ${ }^{+}$Treg) studies. Mechanisms are listed in red boxes, question marks indicate unknown mechanisms $(53,54,114,124)$. (b) M-MDSCs were sorted based on their cell surface expression of Ly6C and CD11b (112). Lines indicate suppressive relationships based on in vitro studies, with line thickness reflecting the magnitude of the suppression. The iNOS dependency of these relationships is listed in red boxes, with unknown dependence in italics (112). iNOS, inducible nitric oxide synthase; MDSCs, myeloidderived suppressor cells; PNT, peroxynitrite; SO, superoxide; TGF- $\beta$, transforming growth factor beta; Tregs, regulatory T cells; VISTA, V-domain Ig suppressor of T cell activation. Color images available online at www.liebertpub.com/vim

In the murine gammaherpesvirus (MHV-68) model, splenic $\mathrm{CD} 11 \mathrm{~b}^{+} \mathrm{GR} 1^{+}$cells accumulated during the latent stage of infection, with a preferential accumulation of $\mathrm{Ly} 6 \mathrm{G}^{+}$cells (104). However, these cells from MHV-68-infected mice did not demonstrate suppressive activity ex vivo (104), implying they were not MDSCs and/or may not modulate antiviral activity in this system. Furthermore, cultures containing $\mathrm{CD}_{11} \mathrm{~b}^{+} \mathrm{GR} 1^{+}$cells from MHV-68-infected mice did not upregulate iNOS or Arg1 activity (104).

\section{Relationships of MDSCs to Disease, and Intervention Strategies with MDSCs as Targets of Immunotherapy}

\section{MDSCs as correlates of disease}

During viral infections, MDSC accumulation and/or activity often correlate with disease parameters. For example, increased MDSC frequency and Arg1 activity corresponded with the extent of HIV-related pathogenesis, including reduced $\mathrm{CD}^{+} \mathrm{T}$ cell counts and increased viral load $(24,25,122,155)$. MDSC 


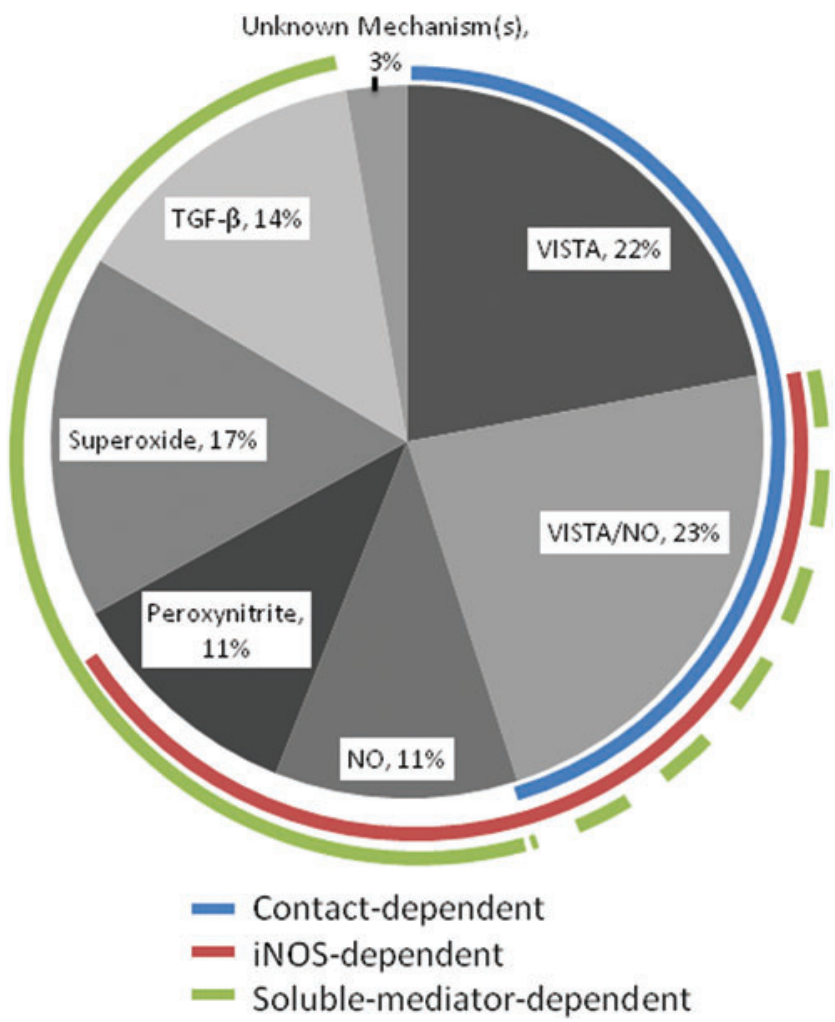

FIG. 2. M-MDSC mechanisms of B cell suppression. Based on the studies presented in references $(53,54,124)$, including experiments showing additivity, known mechanisms of LP-BM5-expanded wild-type murine M-MDSCs are summarized with estimates of their relative contributions to their suppression of B cells (with acknowledgment of the difficulty in accurately summing up the proportionality of such mechanisms due to the likely plasticity and compensation of molecular suppressive mechanisms). Color images available online at www.liebertpub.com/vim

frequencies decreased on initiation of HAART in HIV patients and in SIV-infected macaques, further implicating MDSCs as indicators of HIV/SIV disease level $(49,122,155)$. Similarly, antiviral therapy decreased MDSC frequencies in the blood of HCV patients (14). In the LP-BM5 MAIDS model, M-MDSC frequency also paralleled altered disease severity, with $P D-1$, $P D-L 1$, and $I L-10$ knockout mice showing increased disease severity along with increased MDSC frequency when compared with wild-type mice (53).

During HSV-1 and HSV-2 infection of mice, cells phenotypically resembling MDSCs infiltrated the cornea (34) and skin $(40,164)$. In one study, increased herpes simplex keratitis (HSK) and viral titers were observed in HSV-1-infected $\mathrm{Kit}^{\mathrm{W}-\mathrm{sh}}$ mice (that lack CD $31^{+}$mast cells), compared to wildtype mice (130). This increased disease correlated with increased influx of G-MDSC-like/PMN cells into the corneas of HSV-1-infected $\mathrm{Kit}^{\mathrm{W}-\mathrm{sh}}$ mice (130), and implied that MDSCs may dampen the immune responses that normally reduce viral replication. However, functional assays are difficult to perform on MDSCs from the corneal and skin infection models due to their low frequency and challenges in isolation. It will be important to determine whether different subsets of MDSCs (or other myeloid cells) infiltrate to different sites of infection or in response to different HSV species.
Despite accumulation of MDSCs during viral infections, it remains unclear what role these cells play in these diseases. MMDSCs accumulated within the liver (170) and PBMCs $(14,52,106,128,149)$ of HCV-infected patients. Some studies found a correlation between M-MDSC levels and HCV viral load or other disease parameters [including two of the studies of the PBMC (14,52) and one of the liver (170)], while other studies of the PBMC compartment found no correlation $(106,128)$.

\section{MDSCs as targets of viral replication}

In addition to suppressing antiviral immune responses, MMDSCs can also be sites of viral replication. M-MDSCs from healthy and HIV-infected patients express the HIV-1 entry receptor $\mathrm{CD}^{+}$, as well as the coreceptors CCR5 and CXCR4, rendering these MDSCs targets for HIV infection (122). MMDSCs from healthy subjects could be infected de novo with HIV strains in vitro, and HIV env and gag genes were detected in MDSCs from $\mathrm{HIV}^{+}$patients (122). In addition to being direct targets of HIV infection, MDSCs increased ex vivo viral replication in cocultured $\mathrm{CD}^{+} \mathrm{T}$ cells (122).

The ubiquitously expressed CAT-1 is the mouse cell receptor for LP-BM5 (59), and conceptually renders M-MDSCs, among many other cell types, susceptible to LPBM5 infection. LP-BM5 retroviral gag gene expression (by qRT-PCR) and titers of LP-BM5 retrovirus infectious centers have readily been detected in highly enriched Ly6Gdepleted, CD11b-enriched M-MDSCs from LP-BM5infected mice (53). Collectively, these data support the idea that MDSCs may be active targets for retroviral replication.

\section{Factors involved in MDSC expansion}

Several tumor-derived factors may contribute to MDSC activation and recruitment, including prostaglandins, IL-6, IL$1 \beta$, IFN- $\gamma$ stem cell factor, granulocyte macrophage colonystimulating factor (CSF), macrophage CSF (M-CSF), vascular endothelial growth factor, and markers of cellular stress (i.e., MHC I chain-related molecule) $(28,47,104,150,167)$. Prostaglandin E2 (PGE2) inhibited differentiation of dendritic cells (DCs) and instead caused IMCs to adopt an MDSC phenotype (110). A positive feedback loop between PGE2 and COX2 (a regulator of PGE2 synthesis) induced transcription of the immunosuppressive molecules $i N O S, I D O$, and $I L-10(55,105$, 151). IL-6 and M-CSF were also implicated in myeloid cell development and inhibited differentiation into DCs $(43,45,77)$.

IL-6 levels have been shown to directly correlate with MDSC numbers in vivo (135). Many of these molecules signal through STAT3, which also upregulates S100A9, a myeloid-related protein that prevented DC maturation resulting in accumulation of MDSCs $(21,103,166)$. IL-10, conversely, inhibited MDSC-expansion by blocking IL-6 signaling through STAT3 (83). Several of these and other proinflammatory and damage-associated signals are also upregulated during chronic viral infections, and may play analogous roles in MDSC expansion.

Changes to the tumor microenvironment, including acidosis, hypoxia, and alterations in glucose levels, can also modulate MDSC activity and phenotype (150). For example, hypoxia results in increased HIF- $1 \alpha$ expression through decreased degradation and increased translation (169), which upregulated iNOS and Arg1 (27,81). Endoplasmic reticulum stress has also been shown to upregulate iNOS 
and Arg1, as well as the ROS producing enzyme NADPH oxidase (82).

The factors involved in driving MDSC expansion and/or differentiation during viral infections, including cytokines and chemokines, remain less clear. During chronic HBV infection, the frequency of MDSCs correlated with the level of hepatitis B surface $\mathrm{Ag}$ ( $\mathrm{HBsAg}$ ), and culture of human PBMCs with HBsAg led to differentiation of these cells to MDSCs in an ERK/IL-6/STAT3 signaling-dependent manner, indicating that viral antigen may play a role in triggering the expansion of MDSCs (39).

Similarly, HCV core protein was able to induce generation of MDSCs from PBMCs by activating STAT3 and the PI3K pathway $(118,148,149)$. During HCV infection, expression of several miRNAs was altered in $\mathrm{CD}_{3} 3^{+}$myeloid cells, including miR-124, which was downregulated, in part, due to HCV-induced overexpression of STAT-3 (127). Downregulation of miR-124 correlated with increased levels of IL-10 and TGF- $\beta$ expression by MDSCs (127).

In vitro, IL-6 mediated M-MDSC expansion from PBMCs by HIV gp120 stimulation $(33,50)$. Direct HIV infection or the presence of the HIV-1-derived transcriptional transactivator (Tat) protein also induced M-MDSC expansion in vitro (122). Analysis of transcriptional gene targets of Tat pointed to IL- 6 and TGF- $\beta$ as candidates for mediating Tat-induced MDSC expansion (122). Immune activation of other cells by viruses may also cause MDSC expansion, as was seen with human hepatic stellate cells activated by inflammatory stimuli, which induced development of M-MDSCs through cell contact and CD44 (63).

In tumor systems, cross talk between Tregs and MDSCs was observed, and factors produced by Tregs, such as TGF- $\beta$ or IL-10, modulated MDSC expansion, either directly or by changing the inflammatory milieu $(68,89)$. In macaques vaccinated with a recombinant modified vaccinia Ankara (MVA) vector, increased plasma latent TGF- $\beta$ was observed, which positively correlated with PBMC MDSC frequencies, compared to naive animals-all this consistent with a possible role for TGF- $\beta$ in MDSC expansion (146). Additional unpublished data from the same group implied that neutralizing TGF- $\beta$, using an intrarectal anti-TGF- $\beta \mathrm{Ab}$ during MVA vaccination, reduced MDSC frequency. The source of the TGF- $\beta$, however, was not determined. Although $\mathrm{CD}^{+}$Tregs are a potential source of TGF- $\beta$, no increase in $\mathrm{CD}^{+}{ }^{+}$Treg numbers was seen on vaccination (146). Nevertheless, the amount of TGF- $\beta$ produced on a per Treg basis may have increased.

In the LP-BM5 murine retroviral system, M-MDSC frequency and suppressive activity by M-MDSCs increased in the absence of $I L-10$ and $P D-1 / P D-L 1$ (knockout mice), supporting a negative regulatory role for these pathways in M-MDSC activation (53). Furthermore, this retroviral system highlights a reciprocal negative regulation between M-MDSC and Tregs. CD4 ${ }^{+}$FoxP $^{+}$Tregs from LP-BM5infected mice were potent producers of IL-10, which was inhibited by MDSCs (114). Conversely, mice depleted of natural $\mathrm{FoxP}^{+}$Treg (nTregs), using an adoptive transfer model, had increased M-MDSC frequencies and increased M-MDSC suppressive capacity selectively for $\mathrm{T}$ cell responses, compared to nondepleted LP-BM5-infected control mice (114). These results indicated that $\mathrm{CD} 4^{+} \mathrm{FoxP}^{+}$Tregs normally decreased M-MDSC expansion and activation in
LP-BM5-infected mice (either directly or through their effects on cytokine secretion and functions of other immune cells), potentially in an IL-10-dependent manner.

IL-10 was also important for reducing HSK disease severity, but here, $\mathrm{CD} 11 \mathrm{~b}^{+} \mathrm{GR} 1^{+}$cells were the major producers of corneal IL-10 (131). IL- $10^{-/-}$mice with HSK disease had increased disease driven by corneal $\mathrm{T}$ cell production of IFN- $\gamma$ and IL-17 (131), indicating that IL-10 from $\mathrm{CD} 11 \mathrm{~b}^{+} \mathrm{GR} 1^{+}$cells may normally act to control HSK disease caused by such $\mathrm{T}$ cell responses. Results in Tregdepleted HSK mice supported a role for Tregs as important positive regulators of MDSC recruitment and function during HSV corneal infection (131).

\section{Factors contributing to MDSC recruitment/trafficking}

Several molecules involved in the accumulation and expansion have also been shown to play important roles in MDSC trafficking in tumor systems. For example, in addition to its role in preventing DC maturation, S100A9 stimulated recruitment of MDSCs (142). PGE2, another factor that decreased DC maturation, induced expression of CXCR4 and its ligand, CXCL12, in a COX2-dependent manner, which drove accumulation of MDSC at tumor sites $(38,111)$. TGF- $\beta$ also upregulated CXCR4 on MDSCs, resulting in increased recruitment to tumors, through microRNA-494 $(6,91,168)$. Similarly, hypoxia was shown to increase CCL26 expression on cancer cells, leading to recruitment of $\mathrm{CX}_{3} \mathrm{CR} 1$-expressing MDSCs (22).

In some tumor systems, CCL2-dependent attraction of $\mathrm{CCR} 2^{+}$cells, including some TAMs and MDSC subsets, was required for recruitment to tumor sites $(16,67)$. CCR2-dependent pathways were also required for recruitment of MDSC-LCs (GR $1{ }^{1 \mathrm{~L}} \mathrm{Ly} 6 \mathrm{C}^{\mathrm{hi}} \mathrm{CD} 11 \mathrm{~b}^{+}$and GR $1{ }^{\text {int }} \mathrm{Ly} 6 \mathrm{C}^{\mathrm{hi}} \mathrm{CD} 11 \mathrm{~b}^{+}$, respectively) during MCMV and LCMV infections (30,109). Despite established MCMV infection and progression to latency, viral clearance was enhanced in $\mathrm{Ccr} 2^{-/-} \mathrm{Ccl} 2^{-/-}$mice, which exhibit impaired MDSC recruitment (30), implying that MDSCs inhibit immune responses contributing to MCMV clearance.

Pathogen-associated molecular patterns and cytokines can also affect MDSC recruitment. Mortality and MDSC infiltrates to the lung increased in the absence of TLR7 in IAVinfected mice (72), suggesting that in wild-type mice downstream TLR7 signaling events may limit MDSC recruitment and dampen immune responses associated with disease pathology. Supporting such an inhibitory role for TLR7/8 ligation, M-MDSCs from cancer patients differentiated into M1-like macrophages and displayed decreased immunosuppressive capabilities when treated with TLR7/8 agonists (157). Primary hepatic stellate cells, in contrast, promoted G-MDSC expansion in vitro and may have supported the recruitment of G-MDSCs to the liver of chronically HBV-infected patients (116). Innate immune sensing of viruses, and the downstream signaling via these pathways, may thus contribute to determining MDSC frequencies during viral infections.

Collectively, these studies in viral systems highlight and implicate several factors involved during MDSC recruitment and/or activation during viral infection: (1) viral sensors and their downstream signaling pathways, (2) viral proteins that normally alter adaptive and/or innate immune responses, and (3) virus-induced cytokines and/or chemokines. 
Phenotype and functional M-MDSC subsets and dynamic interactions of M-MDSCs with other immune cells: $L P-B M 5$ retroviral pathogenesis

As described above, in the LP-BM5 retrovirus MAIDS model, it was determined that M-MDSCs derived from infected mice suppressed both $\mathrm{T}$ and $\mathrm{B}$ cell responses (Fig. 1a, b) (53). Suppression of $\mathrm{T}$ cell responses by LP-BM5expanded M-MDSCs was iNOS dependent, however, only part of the suppression of $\mathrm{B}$ cell responses was dependent on iNOS/NO (53).

VISTA, a newly identified negative checkpoint regulator ligand, expressed on several hematopoietic cell types, including myeloid lineages cells (158), was expressed on MMDSCs from LP-BM5-infected mice (54). Suppression of B cell, but not T cell, responses by M-MDSCs from LP-BM5infected mice was partially blocked by the addition of blocking anti-VISTA mAb (54). Use of iNOS and VISTA blocking reagents in combination revealed that the VISTA and iNOS/NO pathways were distinguishable and were the two primary effector mechanisms required for suppression by M-MDSCs (54). In support of (in part) a direct effector suppressive mechanism, a VISTA-Ig chimeric fusion protein also inhibited B cell responses (54).

In addition, soluble mediators, including TGF- $\beta$, superoxide anion, peroxynitrite, and NO, contributed to the suppression of B cell responses by LP-BM5-derived M-MDSCs (124) (Fig. 2). However, there was no evidence for involvement of either $\mathrm{H}_{2} \mathrm{O}_{2}$ or cysteine depletion (124).

M-MDSCs from LP-BM5 retrovirus-infected mice were sorted into several populations and subpopulations, as delineated by the cell surface densities of CD11b and/or Ly6C expression, and these M-MDSC subsets revealed differential suppression of T versus B cell responsiveness (Fig. 1b) (112). The $\mathrm{Ly} 6 \mathrm{C}^{+/ h i} \mathrm{M}-\mathrm{MDSC}$ subpopulation was highly suppressive of both $\mathrm{T}$ and $\mathrm{B}$ cell responses, and suppression was mediated completely or, in part, respectively, by iNOS/NO (112). In contrast, suppression of B cell responses by the Ly6 $\mathrm{C}^{+/ \mathrm{mid}} \mathrm{M}-\mathrm{MDSC}$ subpopulation was undetectable, although this same subset of M-MDSCs readily suppressed $\mathrm{T}$ cell responsiveness (112). Consistent with this selectivity for $\mathrm{T}$ cell targets, the suppression of $\mathrm{T}$ cell responses by this Ly6C ${ }^{+/ m i d}$ M-MDSC subpopulation was iNOS/NO independent (112), however, the mechanism(s) used to selectively inhibit $\mathrm{T}$ cell responsiveness is yet to be identified.

Following LP-BM5 infection and using in vivo adoptive transfers of selective $\mathrm{CD} 4^{+} \mathrm{T}$ cell subsets, it was observed that $\mathrm{CD}^{+} \mathrm{FoxP}^{+}$natural Tregs modulated both the phenotype and function of the M-MDSC population. The suppressive activity toward $\mathrm{T}$ cells was significantly increased when M-MDSCs were obtained from nTreg-depleted, LP-BM5infected mice, compared to M-MDSCs derived from nTregintact mice (114). In contrast, suppression of B cell responses was unaffected by nTreg depletion (114). The Ly6C ${ }^{\text {mid }}$ population selectively expanded in the absence of nTregs. As just described with sorted subsets in nTreg-intact mice, this subpopulation suppressed $\mathrm{T}$ but not $\mathrm{B}$ cell responses in an iNOS/ NO-independent manner $(112,114)$.

The mechanism by which FoxP3 ${ }^{+}$Tregs downregulated the LP-BM5-derived M-MDSC compartment in vivo remains to be determined, however, studies from this and other systems suggest that IL-10 could be a potential can- didate $(53,114)$. IL-10 can induce Arg1 expression and conversely suppress iNOS expression $(56,100)$. Therefore, early IL-10 production by Tregs, and potentially other cell types, during LP-BM5 infection may decrease iNOS expression in M-MDSCs. LP-BM5-induced M-MDSCs suppressed in vitro IL-10 production by both FoxP3 ${ }^{+}$Treg (114) and regulatory B cells (124), consistent with a reciprocal negative relationship between M-MDSCs and regulatory lymphocytes during LP-BM5 infection.

\section{Direct targeting of MDSCs in vivo}

The LP-BM5 system demonstrates the complex involvement of MDSCs in disease pathology and indicates potential complications that may arise when using immunotherapies targeting MDSCs. Despite these obstacles, several approaches have been attempted, with varying degrees of success, to target MDSCs in tumor systems (47,117). Although (to our knowledge) the effects of MDSC-targeted therapies in viral infections have not been substantially investigated, these methods may also be useful in targeting MDSCs in infection models, as follows.

MDSCs as therapeutic targets during viral infection. In many viral diseases, MDSC numbers correlated with pathogenesis, including in HIV $(24,25,122,155)$, LP-BM5 (53), and more than half of the reported studies in HCV $(14,52,170)$. Conversely, antiviral therapies, which decrease pathology, were associated with decreased MDSC numbers in HCV (14) and HIV/SIV $(49,122,155)$. One of the roles of MDSCs in pathogenesis is to decrease antiviral immunity, possibly to limit immunopathological damage. Expansion of MDSCs is observed in chronic, but not acute LCMV, indicating that MDSCs may contribute to the establishment of chronic infection (109).

In several models where MDSCs were intentionally reduced, antiviral responses and viral clearance increased, including via anti-GR-1 mAb therapy for LCMV (109) and HCV (164). MCMV-infected CCR2/CCL2 double knockout mice, which had impaired MDSC recruitment, also exhibited increased viral clearance (30). SIV vaccines using MVA virus as a vector and adjuvant resulted in increased MDSC frequency when compared to vaccination with adjuvant alone (146). This increase in MDSCs was accompanied by increased viral load, also implicating MDSCs in suppressing antiviral immunity (146). In these virus infections where MDSCs decrease protective antiviral responses, immune therapies aimed at decreasing MDSC numbers or function may aid in viral clearance and prevent chronic infection.

On the contrary, MDSCs show evidence of being protective to damage sustained in certain viral infections. During vaccinia infection, depletion of MDSCs with anti-Gr-1 led to increased mortality and was attributed to increased NK cell activity and IFN- $\gamma$ production, indicating the MDSC may prevent lethal immunopathology (42). Similarly, in HBVinfected patients, decreased MDSC frequencies correlated with hepatic flares (116). In viruses that cause severe immunopathology, increasing MDSC numbers may prove beneficial. Robust MDSC function may also benefit the host by decreasing the number of other cell types available for productive infection, especially in cases such as HIV (122) and LP-BM5 (59), when immune cells are targets for infection and are required for pathogenesis. 
In yet other cases, evidence indicates that MDSCs may play dual roles-being both harmful to the host (preventing antiviral immunity) and beneficial (preventing immunopathology). Kit ${ }^{\mathrm{W}-\mathrm{sh}}$ mice (which lack $\mathrm{CD} 31^{+}$mast cells) infected with HSV-1 had increased G-MDSC recruitment to the cornea, and increased HSK and viral titers, indicating that the G-MDSCs may dampen HSV-1 antiviral responses (130). However, IL-10 is important for reducing HSV-1induced immunopathology in the cornea, and MDSCs are the major source of IL-10 production (131). Immunotherapy targeting MDSCs may be helpful in cases where one of these functions needs to be increased or decreased.

Blocking MDSC expansion/generation. There are a variety of pharmacological approaches that may be able to block expansion or generation of MDSCs in vivo. For example, tasquinimod binds to and inhibits signaling by S100A9, a molecule known to be important for accumulation and activation of MDSCs (126). In murine prostate tumor models, tasquinimod treatment led to decreased MDSC numbers and functions, and increased antitumor responses (137). This treatment was well tolerated, slowed tumor progression, and increased survival in phase II trials in castrate-resistant prostate cancer patients (119). These data indicate that tasquinimod may also be a beneficial therapy for viral infections, in which S100A9 signaling is involved in MDSC expansion.

As mentioned above, the PGE2-COX2 pathway has also been implicated in MDSC generation $(110,111)$. COX2 inhibitors have been tested in a variety of cancers and have reduced tumor growth, possibly due, in part, to decreased MDSC generation $(17,156,160)$. Conversely, COX2 promoters, such as the FDA-approved drug finasteride, were able to increase MDSC numbers and may be useful when immunosuppressive therapy is desired (172).

Ablating TNF- $\alpha$, another factor involved in MDSC induction, using the clinically approved TNF blockers etanercept and infliximab, was shown to reduce MDSC accumulation and transplantable tumor growth in mice with the human TNF- $\alpha$ gene substituted for the murine gene (1). The clinically approved cancer therapeutics ibrutinib and sunitinib inhibited tyrosine kinases present in MDSCs and prevented MDSC generation, migration, and function in several murine tumor models $(64,145)$.

Inducing MDSC differentiation and maturation. As MDSCs are IMC populations that include precursors of macrophages and myeloid DCs, one potential therapeutic strategy is to induce differentiation of these cells to more mature, nonsuppressive DCs and macrophages (47): for example, using alltrans retinoic acid (ATRA) $(45,61,78)$. ATRA treatment successfully increased $\mathrm{T}$ cell responsiveness and decreased MDSC numbers (with MDSCs differentiating into DCs, macrophages, and a small number of granulocytes) in a variety of murine tumor models (78). These changes were found to be independent of the effects of ATRA on tumor cells, indicating that this therapy could potentially be used in viral systems (78). Clinical trials in patients with lung cancer have verified that ATRA decreased MDSC numbers and increased p53expressing DC vaccine efficacy (70). In a murine model of postsepsis immunosuppression, ATRA administration concurrently resulted in decreased MDSC numbers and increased $\mathrm{CD}^{+}$and $\mathrm{CD}^{+} \mathrm{T}$ cell numbers (96).
MDSCs can also be differentiated into mature myeloid cells using paclitaxel or potent stimulation by pathogenassociated molecular patterns, such as $\mathrm{CpG}$ oligonucleotides $(97,139)$. Cryothermal therapy, in which cooling and heating are alternated, has been shown to lead to release of Hsp70, which induced differentiation of MDSCs into mature DCs, allowing for increased survival and decreased metastasis in a murine mammary carcinoma model (175).

Depleting MDSCs. In the Theiler's murine encephalomyelitis virus disease model, deletion of $\mathrm{GR} 1^{+}$MDSCs with the anti-GR 1 antibody delayed onset and reduced clinical development of demyelinating disease (7). Polyfunctional LCMV-specific $\mathrm{T}$ cells increased coordinately with antiGR-1-mediated diminishment of MDSCs in LCMV-infected mice, with a trend toward decreased viral loads (109). However, MDSC reduction during vaccinia virus infection in mice instead led to increased mortality and was associated with increased NK cell activation and IFN- $\gamma$ inflammatory responses, rather than increased viral titers (42).

The anti-GR1 antibody binds both granulocytic and monocytic MDSC subsets, but can also bind monocytes and mature PMNs, leading to broad myeloid cell depletion. Such broad targeting could have deleterious effects, particularly if nonMDSC targets, or one of the subsets of MDSCs, are beneficial to viral clearance or prevention of immunopathology. In an HSV-1 skin flank infection model, mice depleted of $\mathrm{GR} 1^{+}$cells had increased viral loads and lesion severity. This effect was not observed in mice depleted of $\mathrm{Ly}_{6 \mathrm{G}}{ }^{+}$cells (including neutrophils and G-MDSCs) (164), suggesting that Ly6C ${ }^{+}$ $\mathrm{GR}^{+}$cells (M-MDSCs) may modulate the immune response needed to control HSV-1 viral replication and associated immune pathology. A similar pattern of an inferred role for Ly6C ${ }^{+}$M-MDSCs was observed by the same research group using an intranasal HSV-1 infection model (165).

Administration of the chemotherapeutic agent gemcitabine, a nucleoside analog that lowers MDSC numbers in the spleen by inducing apoptosis and necrosis, decreased MDSCs in murine tumor models $(37,80,147)$.

Blocking suppressive mechanisms. Blocking the suppressive mechanism(s) of MDSCs could be an attractive alternative to MDSC depletion. Specific inhibitors exist to block Arg1, iNOS, and ROS production. For example, nitroaspirin has been found to limit Arg1 and iNOS activity in splenic MDSCs (32). Phosphodiesterase-5 inhibitors such as sildenafil, tadalafil, and vardenafil, which limit Arg1 and iNOS activity, have been shown to restore $\mathrm{T}$ cell antitumor immunity in murine models and in a patients with end-stage relapsed/refractory multiple myeloma $(108,134)$.

However, the plasticity of MDSCs and the variety of potential suppressive mechanisms may allow them to compensate, when certain mechanisms are blocked, by upregulating other mechanisms. Such compensation was observed with comprehensive mechanistic studies, including wild-type versus iNOS/VISTA double knockout MDSCs in the LP-BM5 murine retrovirus model (124). This plasticity and the observation that MDSCs may use multiple suppressive mechanisms (Figs. 1a and 2) indicate that inhibition of certain mechanisms may not have as profound an effect as blocking expansion, inducing differentiation, or depleting MDSCs. 
Vaccination. MDSC immune responses were altered following some vaccination regimens. As mentioned above, in an SIV vaccination study, increased frequencies of MDSCs, correlating with increased viral loads, were observed in animals treated with MVA vector plus adjuvantvaccinated compared to the adjuvant-alone group (146). The MVA vector vaccine-induced MDSCs inhibited protective immune responses, leading to decreased vaccine efficacy (146). Decreased CD ${ }^{+}$CTL activity attributed to increased MDSCs was also detected in mice immunized with an infectious recombinant vaccinia virus encoding IL-2 (11). CD $11 b^{+}$Ly6C $^{\text {int }}{\text { Ly } 6 G^{-}}^{-}$M-MDSCs accumulated at the site of bacillus Calmette-Guérin (BCG) vaccination and were associated with dampened early $\mathrm{T}$ cell priming responses (95).

Other viruses commonly used in vaccinations as vectors and as recombinants, such as vesicular stomatitis virus, have also been shown to induce MDSC accumulation (42,90). Certain adjuvants, including the dsRNA synthetic analog poly(I:C) (90), complete Freund adjuvant (161), and the lipopolysaccharidederived TLR4 agonist monophosphoryl lipid A (19), also induced MDSC expansion. Conversely, the TLR7/8 antagonist, resiquimod, caused MDSC differentiation into less suppressive, mature myeloid cells (84). Conflicting reports indicate that $\mathrm{CpG}$ may either expand MDSCs $(18,99)$ or increase their differentiation into macrophages (139).

\section{Effects on microbial pathogenesis}

In addition to suppressing immune cells, MDSCs can directly alter microbial pathogenesis. For example, NO is known to have antimicrobial and antiparasitic activity $(71,102)$. In the context of viral infections, NO production or arginine depletion can alter/inhibit viral replication, cause immunopathology, and/or promote viral persistence, in part, by modifying innate and/or adaptive immune responses (13).

Relative to the mechanism(s) utilized by MDSCs to suppress immune cells during viral infection, some of these molecular mechanisms may have diverse "off-target" effectsthat is, on the virus itself, nonimmune cells, or immune cells unassociated with protection. While blocking an MDSC suppressive mechanism(s) may lead to compensatory inhibitory mechanisms, even direct depletion could result in unexpected and undesired consequences such as upregulation of other inhibitory cells (e.g., IL-10-producing $\mathrm{CD}^{+}$Treg cells). This consequence is consistent with the observation that during LPBM5 retrovirus infection, Tregs are normally either directly or indirectly suppressed by MDSCs (114).

\section{Conclusions and Perspectives}

Several of the studies exploring MDSCs in patients consist of small sample sizes, which limit the interpretation of results. In addition, MDSCs isolated ex vivo from fresh or frozen human PBMC samples, or derived under potentially nonphysiological in vitro conditions, may alter the phenotype and/ or functionality of these MDSCs. These difficulties in human systems make murine studies an attractive alternative. However, confounding factors, such as the disparate use of MDSC markers, make comparing human and murine studies challenging. Additional studies are needed to fully understand differences between murine and human MDSCs and to more effectively design safe and beneficial MDSC-related therapies.
While MDSCs are subdivided into monocytic and granulocytic subsets, these cell compartments remain highly heterogeneous. Phenotypic characteristics used to identify MDSCs are similar to other immune cells, including neutrophils, DCs, monocytes, and macrophages. Suppressive mechanisms may vary in different infections, with many MDSC populations/ subpopulations utilizing multiple mechanisms. Inhibition of one suppressive mechanism may lead to upregulation of other mechanisms. In comparison to the heavily studied role of MDSCs in cancer [reviewed in Refs. $(101,150)$ ], their roles in viral infections remain relatively uncertain. However, there is growing enthusiasm that sufficient similarities in MDSCs exist across many different pathologies to allow for more broad therapies targeting MDSCs to attain a better balance of antiviral immunity versus immunopathology.

\section{Acknowledgments}

We thank Kathy Green, David Leib, Edward Usherwood, Brent Berwin, and Yike Jiang for many helpful discussions and technical assistance. This work was supported by Public Health Service Grants from the National Institutes of Health: CA-50157 and a pilot grant P30 GM10345, both to W.R.G. M.A.O. was supported through The American Association of Immunologists Careers in Immunology Fellowship Program. The NIH training grant T32 AI007363 (to Dr. Charles Sentman) provided support to M.A.O. and J.L.R.

Additional support was provided by Core Grant (CA23108) from the National Cancer Institute to the Norris Cotton Cancer Center, and NIH/NCRR NIGMS COBRE P20 (RR16437) and P30 (GM103415) grants: the Center of Biomedical Research Excellence in Molecular, Cellular, and Translation Immunological Research (W.R.G principal investigator).

\section{Author Disclosure Statement}

No competing financial interests exist.

\section{References}

1. Atretkhany K-SN, Nosenko MA, Gogoleva VS, et al. TNF neutralization results in the delay of transplantable tumor growth and reduced MDSC accumulation. Front Immunol 2016;7:147.

2. Aziz DC, Hanna Z, and Jolicoeur P. Severe immunodeficiency disease induced by a defective murine leukaemia virus. Nature 1989;338:505-508.

3. Baptiste S, Chen C, Sindhu H, and Wang J-C. Programmed cell death receptor (PD-1), PD-1 ligand (PD-L1) expression and myeloid derived suppressor cells (MDSC) in myeloid neoplasms implicate the mechanism of IMiD treatment of myelofibrosis. Blood 2013;122:2837-2837.

4. Bennett JA, Rao VS, and Mitchell MS. Systemic bacillus Calmette-Guérin (BCG) activates natural suppressor cells. Proc Natl Acad Sci U S A 1978;75:5142-5144.

5. Beury DW, Parker KH, Nyandjo M, et al. Cross-talk among myeloid-derived suppressor cells, macrophages, and tumor cells impacts the inflammatory milieu of solid tumors. J Leukoc Biol 2014;96:1109-1118.

6. Bierie B, Stover DG, Abel TW, et al. Transforming growth factor-beta regulates mammary carcinoma cell survival and interaction with the adjacent microenvironment. Cancer Res 2008;68:1809-1819.

7. Bowen JL, and Olson JK. Innate immune CD11b+Gr-1+ cells, suppressor cells, affect the immune response during 
Theiler's virus-induced demyelinating disease. J Immunol 2009; 183:6971-6980.

8. Bowers NL, Helton ES, Huijbregts RPH, et al. Immune suppression by neutrophils in HIV-1 infection: role of PDL1/PD-1 pathway. PLoS Pathog 2014;10:e1003993.

9. Brandau S, Trellakis S, Bruderek K, et al. Myeloid-derived suppressor cells in the peripheral blood of cancer patients contain a subset of immature neutrophils with impaired migratory properties. J Leukoc Biol 2011;89:311-317.

10. Bronte V, Brandau S, Chen S-H, et al. Recommendations for myeloid-derived suppressor cell nomenclature and characterization standards. Nat Commun 2016;7:12150.

11. Bronte V, Wang M, Overwijk WW, et al. Apoptotic death of CD8+ T lymphocytes after immunization: induction of a suppressive population of Mac- $1+/ \mathrm{Gr}-1+$ cells. J Immunol 1998;161:5313-5320.

12. Bronte V, and Zanovello P. Regulation of immune responses by L-arginine metabolism. Nat Rev Immunol 2005;5:641-654.

13. Burrack KS, and Morrison TE. The role of myeloid cell activation and arginine metabolism in the pathogenesis of virus-induced diseases. Front Immunol 2014;5:428.

14. Cai W, Qin A, Guo P, et al. Clinical significance and functional studies of myeloid-derived suppressor cells in chronic hepatitis c patients. J Clin Immunol 2013;33:798-808.

15. Casabianca A, Orlandi C, Fraternale A, and Magnani M. A new one-step RT-PCR method for virus quantitation in murine aids. J Virol Methods 2003;110:81-90.

16. Chang AL, Miska J, Wainwright DA, et al. CCL2 produced by the glioma microenvironment is essential for the recruitment of regulatory $\mathrm{T}$ cells and myeloid-derived suppressor cells. Cancer Res 2016;76:5671-5682.

17. Chang C-L, Ma B, Pang X, Wu T-C, and Hung C-F. Treatment with cyclooxygenase- 2 inhibitors enables repeated administration of vaccinia virus for control of ovarian cancer. Mol Ther J Am Soc Gene Ther 2009;17:1365-1372.

18. Chen J, Deng C, Shi Q, et al. CpG oligodeoxynucleotide induces bone marrow precursor cells into myeloid-derived suppressor cells. Mol Med Rep 2013;8:1149-1154.

19. Chen J, Sun B, Zhao X, et al. Monophosphoryl lipid a induces bone marrow precursor cells to differentiate into myeloid-derived suppressor cells. Mol Med Rep 2013;8: 1074-1078.

20. Chen S, Akbar SMF, Abe M, Hiasa Y, and Onji M. Immunosuppressive functions of hepatic myeloid-derived suppressor cells of normal mice and in a murine model of chronic hepatitis B virus. Clin Exp Immunol 2011;166: 134-142.

21. Cheng P, Corzo CA, Luetteke N, et al. Inhibition of dendritic cell differentiation and accumulation of myeloidderived suppressor cells in cancer is regulated by s100a9 protein. J Exp Med 2008;205:2235-2249.

22. Chiu DK-C, Xu IM-J, Lai RK-H, et al. Hypoxia induces myeloid-derived suppressor cell recruitment to hepatocellular carcinoma through chemokine ( $\mathrm{C}-\mathrm{C}$ motif) ligand 26. Hepatology 2016;64:797-813.

23. Chou H-S, Hsieh C-C, Charles R, et al. Myeloid-derived suppressor cells (MDSC) protect islet transplants via B7H1 mediated enhancement of $\mathrm{T}$ regulatory cells. Transplantation 2012;93:272-282.

24. Cloke T, Munder M, Taylor G, Müller I, and Kropf P. Characterization of a novel population of low-density granulocytes associated with disease severity in HIV-1 infection. PLoS One 2012;7:e48939.
25. Cloke TE, Garvey L, Choi B-S, et al. Increased level of arginase activity correlates with disease severity in HIVseropositive patients. J Infect Dis 2010;202:374-385.

26. Condamine T, and Gabrilovich DI. Molecular mechanisms regulating myeloid-derived suppressor cell differentiation and function. Trends Immunol 2011;32:19-25.

27. Corzo CA, Condamine T, Lu L, et al. HIF- $1 \alpha$ regulates function and differentiation of myeloid-derived suppressor cells in the tumor microenvironment. J Exp Med 2010; 207:2439-2453.

28. Cripps JG, Wang J, Maria A, Blumenthal I, and Gorham JD. Th1 cells induce the accumulation of myeloid derived suppressor cells in the inflamed TGFb1 knockout mouse liver. Hepatology 2010;52:1350-1359.

29. Crook KR, Jin M, Weeks MF, et al. Myeloid-derived suppressor cells regulate $\mathrm{T}$ cell and $\mathrm{B}$ cell responses during autoimmune disease. J Leukoc Biol 2015;97:573-582.

30. Daley-Bauer LP, Wynn GM, and Mocarski ES. Cytomegalovirus impairs antiviral CD8+ T cell immunity by recruiting inflammatory monocytes. Immunity 2012;37: 122-133.

31. De Santo C, Salio M, Masri SH, et al. Invariant NKT cells reduce the immunosuppressive activity of influenza A virus-induced myeloid-derived suppressor cells in mice and humans. J Clin Invest 2008;118:4036-4048.

32. De Santo C, Serafini P, Marigo I, et al. Nitroaspirin corrects immune dysfunction in tumor-bearing hosts and promotes tumor eradication by cancer vaccination. Proc Natl Acad Sci U S A 2005;102:4185-4190.

33. Del Cornò $\mathrm{M}$, Donninelli $\mathrm{G}$, Varano $\mathrm{B}$, et al. HIV$1 \mathrm{Gp} 120$ activates the STAT3/interleukin-6 axis in primary human monocyte-derived dendritic cells. J Virol 2014;88:11045-11055.

34. Divito SJ, and Hendricks RL. Activated inflammatory infiltrate in HSV-1-infected corneas without herpes stromal keratitis. Invest Ophthalmol Vis Sci 2008;49:1488-1495.

35. Dörner T, Jacobi AM, and Lipsky PE. B cells in autoimmunity. Arthritis Res Ther 2009;11:247.

36. Dörner T, and Radbruch A. Antibodies and B cell memory in viral immunity. Immunity 2007;27:384-392.

37. Draghiciu O, Lubbers J, Nijman HW, and Daemen T. Myeloid derived suppressor cells - an overview of combat strategies to increase immunotherapy efficacy. Oncoimmunology 2015;4:e954829.

38. Eruslanov E, Daurkin I, Vieweg J, Daaka Y, and Kusmartsev S. Aberrant $\mathrm{PGE}_{2}$ metabolism in bladder tumor microenvironment promotes immunosuppressive phenotype of tumor-infiltrating myeloid cells. Int Immunopharmacol 2011;11:848-855.

39. Fang Z, Li J, Yu X, et al. Polarization of monocytic myeloidderived suppressor cells by hepatitis B surface antigen is mediated via ERK/IL-6/STAT3 signaling feedback and restrains the activation of $\mathrm{T}$ cells in chronic hepatitis $\mathrm{B}$ virus infection. J Immunol 2015;195:4873-4883.

40. Fernandez MA, Yu U, Zhang G, et al. Treg depletion attenuates the severity of skin disease from ganglionic spread after HSV-2 flank infection. Virology 2013;447:9-20.

41. Flies $\mathrm{DB}, \mathrm{Wang} \mathrm{S}, \mathrm{Xu} \mathrm{H}$, and Chen L. A monoclonal antibody specific for the programmed death-1 homolog prevents graft versus host disease in mouse models. J Immunol 2011;187:1537-1541.

42. Fortin C, Huang X, and Yang Y. NK cell response to vaccinia virus is regulated by myeloid-derived suppressor cells. J Immunol 2012;189:1843-1849. 
43. Foti E, Ferrandina G, Martucci R, et al. IL-6, M-CSF and IAP cytokines in ovarian cancer: simultaneous assessment of serum levels. Oncology 1999;57:211-215.

44. Fu YX, Watson G, Jimenez JJ, Wang Y, and Lopez DM. Expansion of immunoregulatory macrophages by granulocytemacrophage colony-stimulating factor derived from a murine mammary tumor. Cancer Res 1990;50:227-234.

45. Gabrilovich D. Mechanisms and functional significance of tumour-induced dendritic-cell defects. Nat Rev Immunol 2004;4:941-952.

46. Gabrilovich DI, Bronte V, Chen S-H, et al. The terminology issue for myeloid-derived suppressor cells. Cancer Res 2007;67:425; author reply 426.

47. Gabrilovich DI, and Nagaraj S. Myeloid-derived suppressor cells as regulators of the immune system. Nat Rev Immunol 2009;9:162-174.

48. This reference has been deleted.

49. Gama L, Shirk EN, Russell JN, et al. Expansion of a subset of CD14highCD16negCCR2low/neg monocytes functionally similar to myeloid-derived suppressor cells during SIV and HIV infection. J Leukoc Biol 2012;91:803-816.

50. Garg A, and Spector SA. HIV type 1 Gp120-induced expansion of myeloid derived suppressor cells is dependent on interleukin 6 and suppresses immunity. J Infect Dis 2014;209:441-451.

51. This reference has been deleted.

52. Goh CC, Roggerson KM, Lee H-C, et al. Hepatitis C virus-induced myeloid-derived suppressor cells suppress NK cell IFN- $\gamma$ production by altering cellular metabolism via arginase-1. J Immunol 2016;196:2283-2292.

53. Green KA, Cook WJ, and Green WR. Myeloid-derived suppressor cells in murine retrovirus-induced AIDS inhibit $\mathrm{T}$ - and B-cell responses in vitro that are used to define the immunodeficiency. J Virol 2013;87:2058-2071.

54. Green KA, Wang L, Noelle RJ, and Green WR. Selective involvement of the checkpoint regulator vista in suppression of $\mathrm{B}$-cell, but not $\mathrm{T}$-cell, responsiveness by monocytic myeloid derived suppressor cells from mice infected by an immunodeficiency-causing retrovirus. J Virol 2015;89:9693-9698.

55. Harden JL, and Egilmez NK. Indoleamine 2,3-dioxygenase and dendritic cell tolerogenicity. Immunol Invest 2012;41: 738-764.

56. Hart KM, Bak SP, Alonso A, et al. Phenotypic and functional delineation of murine CX3CR1+ monocytederived cells in Ovarian Cancer. Neoplasia 2009;11:564573.

57. Hart K, Byrne K, Molloy M, Usherwood E, and Berwin B. IL-10 immunomodulation of myeloid cells regulates a murine model of ovarian cancer. T Cell Biol 2011;2:29.

58. Hart KM, Usherwood EJ, and Berwin BL. CX3CR1 delineates temporally and functionally distinct subsets of myeloid-derived suppressor cells in a mouse model of ovarian cancer. Immunol Cell Biol 2014;92:499-508.

59. Hatzoglou M, Fernandez J, Yaman I, and Closs E. Regulation of cationic amino acid transport: the story of the CAT-1 transporter. Annu Rev Nutr 2004;24:377-399.

60. Hayashi K, Hooper LC, Okuno T, Takada Y, and Hooks JJ. Inhibition of HSV-1 by chemoattracted neutrophils: supernatants of corneal epithelial cells (HCE) and macrophages (THP-1) treated with virus components chemoattract neutrophils (PMN), and supernatants of PMN treated with these conditioned media inhibit viral growth. Arch Virol 2012;157:1377-1381.
61. Hengesbach LM, and Hoag KA. Physiological concentrations of retinoic acid favor myeloid dendritic cell development over granulocyte development in cultures of bone marrow cells from mice. J Nutr 2004;134:26532659.

62. Highfill SL, Cui Y, Giles AJ, et al. Disruption of CXCR2mediated MDSC tumor trafficking enhances anti-PD1 efficacy. Sci Transl Med 2014;6:237ra67.

63. Höchst B, Schildberg FA, Sauerborn P, et al. Activated human hepatic stellate cells induce myeloid derived suppressor cells from peripheral blood monocytes in a CD44dependent fashion. J Hepatol 2013;59:528-535.

64. Hooren LV, Georganaki M, Huang H, Mangsbo SM, and Dimberg A. Sunitinib enhances the antitumor responses of agonistic CD40-antibody by reducing MDSCs and synergistically improving endothelial activation and T-cell recruitment. Oncotarget 2016 [Epub ahead of print]; DOI: 10.18632/oncotarget.10364.

65. Hoshi M, Saito K, Hara A, et al. The absence of IDO upregulates type I IFN production, resulting in suppression of viral replication in the retrovirus-infected mouse. J Immunol 2010;185:3305-3312.

66. Huang A, Zhang B, Yan W, et al. Myeloid-derived suppressor cells regulate immune response in patients with chronic hepatitis B virus infection through PD-1-induced IL-10. J Immunol 2014;193:5461-5469.

67. Huang B, Lei Z, Zhao J, et al. CCL2/CCR2 pathway mediates recruitment of myeloid suppressor cells to cancers. Cancer Lett 2007;252:86-92.

68. Huang B, Pan P-Y, Li Q, et al. Gr-1+CD115+ immature myeloid suppressor cells mediate the development of tumor-induced $\mathrm{T}$ regulatory cells and $\mathrm{T}$-cell anergy in tumor-bearing host. Cancer Res 2006;66:1123-1131.

69. Huang L, Ou R, Rabelo de Souza G, et al. Virus infections incite pain hypersensitivity by inducing indoleamine 2,3 dioxygenase. PLoS Pathog 2016;12:e1005615.

70. Iclozan C, Antonia S, Chiappori A, Chen D-T, and Gabrilovich D. Therapeutic regulation of myeloid-derived suppressor cells and immune response to cancer vaccine in patients with extensive stage small cell lung cancer. Cancer Immunol Immunother 2013;62:909-918.

71. James SL. Role of nitric oxide in parasitic infections. Microbiol Rev 1995;59:533-547.

72. Jeisy-Scott V, Davis WG, Patel JR, et al. Increased MDSC accumulation and Th2 biased response to influenza A virus infection in the absence of TLR7 in mice. PLoS One 2011;6:e25242.

73. This reference has been deleted.

74. Kennedy DE, and Knight KL. Inhibition of B lymphopoiesis by adipocytes and IL-1-producing myeloidderived suppressor cells. J Immunol 2015;195:2666-2674.

75. Kennedy DE, Witte PL, and Knight KL. Bone marrow fat and the decline of B lymphopoiesis in rabbits. Dev Comp Immunol 2016;58:30-39.

76. Kong X, Sun R, Chen Y, Wei H, and Tian Z. $\gamma \delta$ t cells drive myeloid-derived suppressor cell-mediated CD8+ $\mathrm{T}$ cell exhaustion in hepatitis B virus-induced immunotolerance. J Immunol 2014;193:1645-1653.

77. Krupitza G, Fritsche R, Dittrich E, et al. Macrophage colony-stimulating factor is expressed by an ovarian carcinoma subline and stimulates the c-myc proto-oncogene. Br J Cancer 1995;72:35-40.

78. Kusmartsev S, Cheng F, Yu B, et al. All-trans-retinoic acid eliminates immature myeloid cells from tumor-bearing mice 
and improves the effect of vaccination. Cancer Res 2003;63:4441-4449.

79. Kusmartsev S, Nefedova Y, Yoder D, and Gabrilovich DI. Antigen-specific inhibition of CD8+ $\mathrm{T}$ cell response by immature myeloid cells in cancer is mediated by reactive oxygen species. J Immunol 2004;172:989-999.

80. Le HK, Graham L, Cha E, et al. Gemcitabine directly inhibits myeloid derived suppressor cells in BALB/c mice bearing 4T1 mammary carcinoma and augments expansion of T cells from tumor-bearing mice. Int Immunopharmacol 2009;9: 900-909.

81. Lechner MG, Megiel C, Russell SM, et al. Functional characterization of human CD33+ and CD11b+ myeloidderived suppressor cell subsets induced from peripheral blood mononuclear cells co-cultured with a diverse set of human tumor cell lines. J Transl Med 2011;9:90.

82. Lee B-R, Chang S-Y, Hong E-H, et al. Elevated endoplasmic reticulum stress reinforced immunosuppression in the tumor microenvironment via myeloid-derived suppressor cells. Oncotarget 2014;5:12331-12345.

83. Lee B-R, Kwon B-E, Hong E-H, et al. Interleukin-10 attenuates tumour growth by inhibiting interleukin-6/signal transducer and activator of transcription 3 signalling in myeloid-derived suppressor cells. Cancer Lett 2016;381: 156-164.

84. Lee M, Park C-S, Lee Y-R, et al. Resiquimod, a TLR7/8 agonist, promotes differentiation of myeloid-derived suppressor cells into macrophages and dendritic cells. Arch Pharm Res 2014;37:1234-1240.

85. Lei G-S, Zhang C, and Lee C-H. Myeloid-derived suppressor cells impair alveolar macrophages through PD-1 receptor ligation during pneumocystis pneumonia. Infect Immun 2015;83:572-582.

86. Lesokhin AM, Hohl TM, Kitano S, et al. Monocytic CCR2(+) myeloid-derived suppressor cells promote immune escape by limiting activated CD8 T-cell infiltration into the tumor microenvironment. Cancer Res 2012;72:876-886.

87. Li H, Han Y, Guo Q, Zhang M, and Cao X. Cancerexpanded myeloid-derived suppressor cells induce anergy of NK cells through membrane-bound TGF- $\beta 1$. J Immunol 2009;182:240-249.

88. Li Z, Pang Y, Gara SK, et al. Gr-1+CD11b+ cells are responsible for tumor promoting effect of TGF- $\beta$ in breast cancer progression. Int J Cancer 2012;131:2584-2595.

89. Lindau D, Gielen P, Kroesen M, Wesseling P, and Adema GJ. The immunosuppressive tumour network: myeloidderived suppressor cells, regulatory $\mathrm{T}$ cells and natural killer T cells. Immunology 2013;138:105-115.

90. Liu C, Zhang $\mathrm{C}$, Lu H, et al. Poly(I:C) induce bone marrow precursor cells into myeloid-derived suppressor cells. Mol Cell Biochem 2011;358:317-323.

91. Liu Y, Lai L, Chen Q, et al. MicroRNA-494 is required for the accumulation and functions of tumor-expanded myeloid-derived suppressor cells via targeting of PTEN. J Immunol 2012;188:5500-5510.

92. Lu L-R, Liu J, Xu Z, et al. Expression and clinical significance of myeloid derived suppressor cells in chronic hepatitis B patients. Asian Pac J Cancer Prev 2014;15:4367-4372.

93. Mandruzzato S, Brandau S, Britten CM, et al. Toward harmonized phenotyping of human myeloid-derived suppressor cells by flow cytometry: results from an interim study. Cancer Immunol Immunother 2016;65:161-169.

94. Marigo I, Dolcetti L, Serafini P, Zanovello P, and Bronte V. Tumor-induced tolerance and immune suppression by mye- loid derived suppressor cells. Immunol Rev 2008;222:162_179.

95. Martino A, Badell E, Abadie V, et al. Mycobacterium bovis bacillus Calmette-Guérin vaccination mobilizes innate myeloid-derived suppressor cells restraining in vivo $\mathrm{T}$ cell priming via IL-1R-dependent nitric oxide production. J Immunol 2010;184:2038-2047.

96. Martire-Greco D, Landoni VI, Chiarella P, et al. All-transretinoic acid improves immunocompetence in a murine model of lipopolysaccharide-induced immunosuppression. Clin Sci (Lond) 2014;126:355-365.

97. Michels T, Shurin GV, Naiditch H, et al. Paclitaxel promotes differentiation of myeloid-derived suppressor cells into dendritic cells in vitro in a TLR4-independent manner. J Immunotoxicol 2012;9:292-300.

98. Mistry SK, Zheng M, Rouse BT, and Morris SM. Induction of arginases I and II in cornea during herpes simplex virus infection. Virus Res 2001;73:177-182.

99. Morecki S, Gelfand Y, Yacovlev E, et al. CpG-induced myeloid CD11b+Gr-1+ cells efficiently suppress $\mathrm{T}$ cellmediated immunoreactivity and graft-versus-host disease in a murine model of allogeneic cell therapy. Biol Blood Marrow Transplant 2008;14:973-984.

100. Munder M, Eichmann K, and Modolell M. Alternative metabolic states in murine macrophages reflected by the nitric oxide synthase/arginase balance: competitive regulation by CD4+ T cells correlates with Th1/Th2 phenotype. J Immunol 1998;160:5347-5354.

101. Nagaraj S, and Gabrilovich DI. Myeloid-derived suppressor cells in human cancer. Cancer J Sudbury Mass 2010;16:348-353.

102. Nathan CF, and Hibbs JB. Role of nitric oxide synthesis in macrophage antimicrobial activity. Curr Opin Immunol 1991;3:65-70.

103. Nefedova Y, Huang M, Kusmartsev S, et al. Hyperactivation of STAT3 is involved in abnormal differentiation of dendritic cells in cancer. J Immunol 2004;172:464-474.

104. Nelson DA, Chauhan VS, Tolbert MD, and Bost KL. Murine gammaherpesvirus-68 expands, but does not activate, CD11b+ Gr-1+ splenocytes in vivo. J Inflamm Lond Engl 2012;9:14.

105. Niedbala W, Alves-Filho JC, Fukada SY, et al. Regulation of type 17 helper T-cell function by nitric oxide during inflammation. Proc Natl Acad Sci U S A 2011;108:92209225.

106. Ning G, She L, Lu L, et al. Analysis of monocytic and granulocytic myeloid-derived suppressor cells subsets in patients with hepatitis $C$ virus infection and their clinical significance. BioMed Res Int 2015;2015:385378.

107. Nonnenmann J, Stirner R, Roider J, et al. Lack of significant elevation of myeloid-derived suppressor cells in peripheral blood of chronically hepatitis $\mathrm{C}$ virus-infected individuals. J Virol 2014;88:7678-7682.

108. Noonan KA, Ghosh N, Rudraraju L, Bui M, and Borrello I. Targeting immune suppression with PDE5 inhibition in end-stage multiple myeloma. Cancer Immunol Res 2014; 2:725-731.

109. Norris BA, Uebelhoer LS, Nakaya HI, et al. Chronic but not acute virus infection induces sustained expansion of myeloid suppressor cell numbers that inhibit viral-specific T cell immunity. Immunity 2013;38:309-321.

110. Obermajer N, Muthuswamy R, Lesnock J, Edwards RP, and Kalinski P. Positive feedback between PGE2 and COX2 redirects the differentiation of human dendritic cells toward 
stable myeloid-derived suppressor cells. Blood 2011;118: 5498-5505.

111. Obermajer N, Muthuswamy R, Odunsi K, Edwards RP, and Kalinski P. PGE(2)-induced CXCL12 production and CXCR4 expression controls the accumulation of human MDSCs in ovarian cancer environment. Cancer Res 2011;71:7463-7470.

112. O'Connor MA, Fu WW, Green KA, and Green WR. Subpopulations of M-MDSCs from mice infected by an immunodeficiency-causing retrovirus and their differential suppression of T- vs B-cell responses. Virology 2015;485: 263-273.

113. O'Connor MA, and Green WR. The role of indoleamine 2,3-dioxygenase in LP-BM5 murine retroviral disease progression. Virol J 2013;10:154.

114. O'Connor MA, Vella JL, and Green WR. Reciprocal relationship of $\mathrm{T}$ regulatory cells and monocytic myeloidderived suppressor cells in LP-BM5 murine retrovirusinduced immunodeficiency. J Gen Virol 2016;97:509-522.

115. Ostrand-Rosenberg S, and Sinha P. Myeloid-derived suppressor cells: linking inflammation and cancer. J Immunol 2009;182:4499-4506.

116. Pallett LJ, Gill US, Quaglia A, et al. Metabolic regulation of hepatitis B immunopathology by myeloid-derived suppressor cells. Nat Med 2015;21:591-600.

117. Pan W, Sun Q, Wang Y, et al. Highlights on mechanisms of drugs targeting MDSCs: providing a novel perspective on cancer treatment. Tumor Biol 2015;36:3159-3169.

118. Pang X, Song H, Zhang Q, Tu Z, and Niu J. Hepatitis C virus regulates the production of monocytic myeloidderived suppressor cells from peripheral blood mononuclear cells through PI3K pathway and autocrine signaling. Clin Immunol 2016;164:57-64.

119. Pili R, Haggman M, Stadler WM, et al. A randomized, multicenter, international phase II study of tasquinimod in chemotherapy naive patients with metastatic castrateresistant prostate cancer (CRPC). ASCO Meet Abstr 2010;28(15 suppl):4510.

120. Poe SL, Arora M, Oriss TB, et al. STAT1-regulated lung MDSC-like cells produce IL-10 and efferocytose apoptotic neutrophils with relevance in resolution of bacterial pneumonia. Mucosal Immunol 2013;6:189-199.

121. Poschke I, Mougiakakos D, Hansson J, Masucci GV, and Kiessling R. Immature immunosuppressive CD14+HLADR-/low cells in melanoma patients are STAT3HI and overexpress CD80, CD83, and DC-sign. Cancer Res 2010; 70:4335-4345.

122. Qin A, Cai W, Pan T, et al. Expansion of monocytic myeloidderived suppressor cells dampens T cell function in HIV-1seropositive individuals. J Virol 2013;87:1477-1490.

123. Quatromoni JG, and Eruslanov E. Tumor-associated macrophages: function, phenotype, and link to prognosis in human lung cancer. Am J Transl Res 2012;4:376-389.

124. Rastad JL, and Green WR. Myeloid-derived suppressor cells in murine aids inhibit B-cell responses in part via soluble mediators including reactive oxygen and nitrogen species, and TGF- $\beta$. Virology 2016;499:9-22.

125. Rath M, Müller I, Kropf P, Closs EI, and Munder M. Metabolism via arginase or nitric oxide synthase: two competing arginine pathways in macrophages. Front Immunol 2014;5:532.

126. Raymond E, Dalgleish A, Damber J-E, Smith M, and Pili R. Mechanisms of action of tasquinimod on the tumour microenvironment. Cancer Chemother Pharmacol 2014;73:1-8.
127. Ren JP, Wang L, Zhao J, et al. Decline of mir-124 in myeloid cells promotes regulatory $\mathrm{T}$ cell development in HCV infection. Immunology 2016. [Epub ahead of print]; DOI: $10.1111 /$ imm.12680.

128. Ren JP, Zhao J, Dai J, et al. Hepatitis C virus-induced myeloidderived suppressor cells regulate $\mathrm{T}$-cell differentiation and function via the signal transducer and activator of transcription 3 pathway. Immunology 2016;148:377-386.

129. Rodríguez PC, and Ochoa AC. Arginine regulation by myeloid derived suppressor cells and tolerance in cancer: mechanisms and therapeutic perspectives. Immunol Rev 2008;222:180-191.

130. Royer DJ, Zheng M, Conrady CD, and Carr DJJ. Granulocytes in ocular HSV-1 infection: opposing roles of mast cells and neutrophils. Invest Ophthalmol Vis Sci 2015;56: 3763-3775.

131. Sarangi PP, Sehrawat S, Suvas S, and Rouse BT. IL-10 and natural regulatory $\mathrm{T}$ cells: two independent antiinflammatory mechanisms in Herpes simplex virus-induced ocular immunopathology. J Immunol 2008;180:6297-6306.

132. Sauer H, Wartenberg M, and Hescheler J. Reactive oxygen species as intracellular messengers during cell growth and differentiation. Cell Physiol Biochem 2001;11:173186.

133. Sawanobori Y, Ueha S, Kurachi M, et al. Chemokinemediated rapid turnover of myeloid-derived suppressor cells in tumor-bearing mice. Blood 2008;111:5457-5466.

134. Serafini P, Meckel K, Kelso M, et al. Phosphodiesterase-5 inhibition augments endogenous antitumor immunity by reducing myeloid-derived suppressor cell function. J Exp Med 2006;203:2691-2702.

135. Sevko A, and Umansky V. Myeloid-derived suppressor cells interact with tumors in terms of myelopoiesis, tumorigenesis and immunosuppression: thick as thieves. J Cancer 2013;4: 3-11.

136. Shaffer AL, Rosenwald A, and Staudt LM. Lymphoid malignancies: the dark side of B-cell differentiation. Nat Rev Immunol 2002;2:920-933.

137. Shen L, Sundstedt A, Ciesielski M, et al. Tasquinimod modulates suppressive myeloid cells and enhances cancer immunotherapies in murine models. Cancer Immunol Res 2015;3:136-148.

138. Shi C, and Pamer EG. Monocyte recruitment during infection and inflammation. Nat Rev Immunol 2011;11: 762-774.

139. Shirota Y, Shirota H, and Klinman DM. Intratumoral injection of $\mathrm{CpG}$ oligonucleotides induces the differentiation and reduces the immunosuppressive activity of myeloid-derived suppressor cells. J Immunol 2012;188:1592-1599.

140. Sica A, and Bronte V. Altered macrophage differentiation and immune dysfunction in tumor development. J Clin Invest 2007;117:1155-1166.

141. Sinha P, Clements VK, Bunt SK, Albelda SM, and OstrandRosenberg S. Cross-talk between myeloid-derived suppressor cells and macrophages subverts tumor immunity toward a type 2 response. J Immunol 2007;179:977-983.

142. Sinha P, Okoro C, Foell D, et al. Proinflammatory s100 proteins regulate the accumulation of myeloid-derived suppressor cells. J Immunol 2008;181:4666-4675.

143. Solito S, Marigo I, Pinton L, et al. Myeloid-derived suppressor cell heterogeneity in human cancers. Ann N Y Acad Sci 2014;1319:47-65.

144. Spaner D, and Bahlo A. B lymphocytes in cancer immunology. In: Medin J, and Fowler D, eds., New York; 
Experimental and Applied Immunotherapy. Humana Press: 2011:37-57.

145. Stiff A, Trikha P, Wesolowski R, et al. Myeloid-derived suppressor cells express Bruton's tyrosine kinase and can be depleted in tumor-bearing hosts by ibrutinib treatment. Cancer Res 2016;76:2125-2136.

146. Sui Y, Hogg A, Wang Y, et al. Vaccine-induced myeloid cell population dampens protective immunity to SIV. J Clin Invest 2014;124:2538-2549.

147. Suzuki E, Kapoor V, Jassar AS, Kaiser LR, and Albelda SM. Gemcitabine selectively eliminates splenic Gr-1+/ CD11b+ myeloid suppressor cells in tumor-bearing animals and enhances antitumor immune activity. Am Assoc Cancer Res 2005;11:6713-6721.

148. Tacke RS, Lee H-C, Goh C, et al. Myeloid suppressor cells induced by hepatitis $\mathrm{C}$ virus suppress $\mathrm{T}$-cell responses through the production of reactive oxygen species. Hepatology 2012;55:343-353.

149. Tacke RS, Tosello-Trampont A, Nguyen V, Mullins DW, and Hahn YS. Extracellular hepatitis $\mathrm{C}$ virus core protein activates STAT3 in human monocytes/macrophages/dendritic cells via an IL-6 autocrine pathway. J Biol Chem 2011;286:10847-10855.

150. Talmadge JE, and Gabrilovich DI. History of myeloidderived suppressor cells. Nat Rev Cancer 2013;13:739-752.

151. Tanikawa T, Wilke CM, Kryczek I, et al. Interleukin-10 ablation promotes tumor development, growth, and metastasis. Cancer Res 2012;72:420-429.

152. Burga A, Thorn M, Nguyen CT, et al. Targeting myeloidderived suppressor cells and the PD-1/PD-11 axis to enhance immunotherapy with anti-CEA designer $\mathrm{T}$ cells for the treatment of colorectal liver metastases. J Clin Oncol. 2013; suppl, abstr 3079.

153. Tayar L, Higo K, Kubo Y, et al. Induction of B-cell lymphoma in BALB/c nude mice with an ecotropic, Btropic helper virus present in the murine aids virus stock. $\mathrm{J}$ Virol 1999;73:1640-1644.

154. Veiga-Parga T, Suryawanshi A, Mulik S, et al. On the role of regulatory $\mathrm{T}$ cells during viral-induced inflammatory lesions. J Immunol 2012;189:5924-5933.

155. Vollbrecht T, Stirner R, Tufman A, et al. Chronic progressive HIV-1 infection is associated with elevated levels of myeloid-derived suppressor cells. AIDS 2012;26:F31-F37.

156. Wang D, and Dubois RN. Eicosanoids and cancer. Nat Rev Cancer 2010;10:181-193.

157. Wang J, Shirota Y, Bayik D, et al. Effect of TLR agonists on the differentiation and function of human monocytic myeloid-derived suppressor cells. J Immunol 2015;194: 4215-4221.

158. Wang L, Rubinstein R, Lines JL, et al. Vista, a novel mouse Ig superfamily ligand that negatively regulates T cell responses. J Exp Med 2011;208:577-592.

159. Wang L, Zhao J, Ren JP, et al. Expansion of myeloid-derived suppressor cells promotes differentiation of regulatory T cells in HIV-1+ individuals. AIDS 2016;30:1521-1531.

160. Wang Q, Takei Y, Kobayashi O, Osada T, and Watanabe $\mathrm{S}$. Cyclooxygenase 2 modulates killing of cytotoxic T lymphocytes by colon cancer cells. J Clin Biochem Nutr 2009;45:163-170.

161. Wang Z, Jiang J, Li Z, et al. A myeloid cell population induced by Freund adjuvant suppresses T-cell-mediated antitumor immunity. J Immunother 2010;33:167-177.

162. Watson GA, Fu YX, and Lopez DM. Splenic macrophages from tumor-bearing mice co-expressing MAC-1 and MAC-2 antigens exert immunoregulatory functions via two distinct mechanisms. J Leukoc Biol 1991;49:126-138.

163. Wink DA, Hines HB, Cheng RYS, et al. Nitric oxide and redox mechanisms in the immune response. J Leukoc Biol 2011;89:873-891.

164. Wojtasiak M, Pickett DL, Tate MD, et al. Gr-1+ cells, but not neutrophils, limit virus replication and lesion development following flank infection of mice with herpes simplex virus type-1. Virology 2010;407:143-151.

165. Wojtasiak M, Pickett DL, Tate MD, et al. Depletion of Gr-1+, but not Ly6G+, immune cells exacerbates virus replication and disease in an intranasal model of herpes simplex virus type 1 infection. J Gen Virol 2010;91(Pt 9): 2158-2166.

166. Wu L, Du H, Li Y, Qu P, and Yan C. Signal transducer and activator of transcription 3 (STAT3C) promotes myeloidderived suppressor cell expansion and immune suppression during lung tumorigenesis. Am J Pathol 2011;179:21312141.

167. Xiao G, Wang X, Sheng J, et al. Soluble NKG2D ligand promotes MDSC expansion and skews macrophage to the alternatively activated phenotype. J Hematol Oncol 2015; $8: 13$.

168. Yang L, Huang J, Ren X, et al. Abrogation of TGFB signaling in mammary carcinomas recruits Gr-1+CD11b+ myeloid cells that promote metastasis. Cancer Cell 2008;13:23-35.

169. Yee Koh M, Spivak-Kroizman TR, and Powis G. HIF-1 regulation: not so easy come, easy go. Trends Biochem Sci 2008;33:526-534.

170. Zeng Q-L, Yang B, Sun H-Q, et al. Myeloid-derived suppressor cells are associated with viral persistence and downregulation of TCR $\zeta$ chain expression on CD8(+) $\mathrm{T}$ cells in chronic hepatitis C patients. Mol Cells 2014;37: 66-73.

171. Zhang B, Wang Z, Wu L, et al. Circulating and tumorinfiltrating myeloid-derived suppressor cells in patients with colorectal carcinoma. PLoS One 2013;8:e57114.

172. Zhang S, Wu K, Liu Y, et al. Finasteride enhances the generation of human myeloid-derived suppressor cells by up-regulating the COX2/PGE2 pathway. PLoS One 2016; 11:e0156549.

173. Zhao W, Xu Y, Xu J, et al. Subsets of myeloid-derived suppressor cells in hepatocellular carcinoma express chemokines and chemokine receptors differentially. Int Immunopharmacol 2015;26:314-321.

174. Zhu J, Huang X, and Yang Y. Myeloid-derived suppressor cells regulate natural killer cell response to adenovirusmediated gene transfer. J Virol 2012;86:13689-13696.

175. Zhu J, Zhang Y, Zhang A, et al. Cryo-thermal therapy elicits potent anti-tumor immunity by inducing extracellular HSP70-dependent MDSC differentiation. Sci Rep 2016;6:27136.

176. Zhu K, Zhang N, Guo N, et al. SSC(high)CD11b(high)Ly6C(high)Ly-6G(low) myeloid cells curtail CD4 T cell response by inducible nitric oxide synthase in murine hepatitis. Int J Biochem Cell Biol 2014;54:89-97.

Address correspondence to: Dr. William R. Green Department of Microbiology and Immunology Geisel School of Medicine at Dartmouth Lebanon, NH 03756

E-mail: william.r.green@dartmouth.edu 